Check for updates

Cite this: Phys. Chem. Chem. Phys., 2020, 22, 26652

Received 14th September 2020, Accepted 3rd November 2020

DOI: $10.1039 / \mathrm{d} 0 \mathrm{cp} 04848 \mathrm{~h}$

rsc.li/pccp

\section{Coupled transport of electrons and protons in a bacterial cytochrome $c$ oxidase-DFT calculated properties compared to structures and spectroscopies}

\author{
Louis Noodleman, (D) *a Wen-Ge Han Du, (D) ${ }^{a}$ Duncan McRee, (D) ${ }^{a}$ Ying Chen, (D) ${ }^{a}$ \\ Teffanie Goh (D) ${ }^{b}$ and Andreas W. Götz (D) ${ }^{b}$
}

\begin{abstract}
After a general introduction to the features and mechanisms of cytochrome $c$ oxidases (CcOs) in mitochondria and aerobic bacteria, we present DFT calculated physical and spectroscopic properties for the catalytic reaction cycle compared with experimental observations in bacterial baz type $\mathrm{CcO}$, also with comparisons/contrasts to $a_{3}$ type CcOs. The Dinuclear Complex (DNC) is the active catalytic reaction center, containing a heme $a_{3} \mathrm{Fe}$ center and a near lying $\mathrm{Cu}$ center (called $\mathrm{Cu}_{\mathrm{B}}$ ) where by successive reduction and protonation, molecular $\mathrm{O}_{2}$ is transformed to two $\mathrm{H}_{2} \mathrm{O}$ molecules, and protons are pumped from an inner region across the membrane to an outer region by transit through the $\mathrm{CcO}$ integral membrane protein. Structures, energies and vibrational frequencies for $\mathrm{Fe}-\mathrm{O}$ and $\mathrm{O}-\mathrm{O}$ modes are calculated by DFT over the catalytic cycle. The calculated DFT frequencies in the DNC of CcO are compared with measured frequencies from Resonance Raman spectroscopy to clarify the composition, geometry, and electronic structures of different intermediates through the reaction cycle, and to trace reaction pathways. X-ray structures of the resting oxidized state are analyzed with reference to the known experimental reaction chemistry and using DFT calculated structures in fitting observed electron density maps. Our calculations lead to a new proposed reaction pathway for coupling the $\mathbf{P}_{\mathbf{R}} \rightarrow \mathbf{F} \rightarrow \mathbf{O}_{\mathbf{H}}$ (ferryl-oxo $\rightarrow$ ferric-hydroxo) pathway to proton pumping by a water shift mechanism. Through this arc of the catalytic cycle, major shifts in $\mathrm{p} K_{\mathrm{a}}$ 's of the special tyrosine and a histidine near the upper water pool activate proton transfer. Additional mechanisms for proton pumping are explored, and the role of the $\mathrm{Cu}_{\mathrm{B}}{ }^{+}$(cuprous state) in controlling access to the dinuclear reaction site is proposed.
\end{abstract}

\section{Introduction-overview}

Cytochrome $c$ oxidase $(\mathrm{CcO})$ (Complex IV) is the terminal electron acceptor in the electron transport chain of mitochondria and of aerobic bacteria. It functions as an oxygen binding, redox driven proton pump across the mitochondrial or paraplasmic membrane, respectively. The functions, mechanisms, and kinetics of various types of $\mathrm{CcO}$ in various organisms ranging from aerobic bacteria to mitochondria in eukaryotic cells, including many types of mammalian cells are complex, and encompass both extensive similarities and important differences. ${ }^{1-6}$ As discussed below, $\mathrm{CcO}$ is part of the electron transport chain, and operates as part of a biological network of integral membrane proteins. ${ }^{7-12}$

\footnotetext{
${ }^{a}$ Department of Integrative Structural and Computational Biology, The Scripps Research Institute, 10550 North Torrey Pines Road, La Jolla, CA 92037, USA. E-mail: lou@scripps.edu

${ }^{b}$ San Diego Supercomputer Center, University of California San Diego, 9500 Gilman Drive MC0505, La Jolla, CA 92093, USA
}

Collectively, Complexes I-IV generate an electrochemical proton gradient which drives the synthesis of ATP. ${ }^{13}$ All cytochrome $c$ oxidases of mitochondria (Type $a a_{3}$ ), or in aerobic bacteria (different types $a a_{3}$ or $b a_{3}$ ) have closely related core subunits, which are the energy generating core of the system, combining redox driven catalytic cycling coupled to proton pumping in the intact membrane embedded protein complex. There are typically three different core energy subunits. Mitochondria also have a number of additional regulatory subunits. To explore the outstanding problems of mechanism and kinetics in these proteins requires a multimodal attack, including X-ray structures, spectroscopies, kinetics, physical properties, and theory/calculations. Our goal is to use quantum chemistry as a unifying framework for exploring important features of geometric and electronic structure throughout the catalytic reaction cycle, encompassing structures, energetics, dynamics, and spectroscopy, relating these to proton pumping mechanisms as well. We will look at one particular bacterial cytochrome $c$ oxidase in detail, cytochrome $b a_{3}$ from Thermus thermophilus (Tt). ${ }^{14}$ 


\section{Mapping system structures, active elements, and pathways}

2.1. Defining the paths and linkages of electron and proton transport through the electron transport chain in mitochondria and aerobic bacteria

The transport of electrons through the electron transport chain common to mammalian mitochondria and aerobic bacteria occurs using mobile electron and proton carriers interacting with the integral membrane Complexes I, II, III, IV (see Fig. 1) embedded in the mitochondrial inner membrane or the periplasmic membrane in aerobic bacteria. ${ }^{13}$ The linkage between these electron carriers and the integral membrane protein Complexes allows proton pumping to occur across the membrane, which lead to the build-up of a transmembrane electrochemical potential. This transmembrane potential difference is the source of most biological energy in the form of ATP. Protons entering the inside of the inner membrane from the outside pass through a rotor in the integral membrane protein Complex V (ATP Synthase) and ATP is synthesized from ADP and inorganic phosphate (Pi) driven by the transmembrane electrochemical potential.

In the electron transport chain, there are two types of mobile carriers. Reduced ubiquinone (called $\mathrm{QH}_{2}$ ) is a relatively small amphiphilic organic cofactor that carries two electrons and two protons $\left(2 \mathrm{e}^{-}, 2 \mathrm{H}^{+}\right)$. By contrast, cytochrome $c$ is a mobile protein carrier of single electrons $\left(1 \mathrm{e}^{-}\right)$only. Reduced ubiquinone is generated from the oxidized form by loss of $\left(2 \mathrm{e}^{-}, \mathrm{H}^{+}\right)$from reduced $\mathrm{NADH}$ in the catalytic process $\mathrm{NADH} \rightarrow \mathrm{NAD}^{+}+2 \mathrm{e}^{-}+\mathrm{H}^{+}$in Complex I. Complex I also pumps protons across the membrane by a complicated electron linked proton transfer process. Complex II also generates $\mathrm{QH}_{2}$ from the oxidized form Q. Further along the electron transport chain, Complex III delivers electrons one at a time to the mobile metalloprotein cytochrome $c$, Cytc(ox) $+1 \mathrm{e}^{-} \rightarrow$ Cytc(red), for the oxidized (heme $\mathrm{Fe}^{3+}$ ) and reduced (heme $\mathrm{Fe}^{2+}$ ) forms respectively.

\subsection{A comparison of two integral membrane proteins-complexes III and IV}

While all of these complexes contribute to generating the membrane potential, and all but Complex II pump protons across the inner membrane, our focus here is on Complex IV, cytochrome $c$ oxidase $(\mathrm{CcO})$ in two relevant types, $a a_{3}$ (A-type, found in mitochondria and in some aerobic bacteria), and $b a_{3}$ (B-type, found in other aerobic bacteria, which will be our main focus).

In the presence of these complicated biological networks, it is very helpful to compare and contrast different systems. A conceptually and historically important comparison and contrast is between Complex III and Complex IV.

In Complex III (Cytochrome $b c_{1}$ ), the redox and proton transfer cycle is called Mitchell's Proton Motive Q Cycle. It is a "Redox Loop Mechanism" with an internal mobile carrier ubiquinone, and large scale movements of membrane domains, in particular, the Rieske iron-sulfur cluster protein fragment, with the $\mathrm{Fe}_{2} \mathrm{~S}_{2}$ cluster and nearby amino acid residues called the head group. ${ }^{15}$

The overall full cycle stoichiometry is

$$
\begin{gathered}
2 \mathrm{QH}_{2}(\text { outer })+\mathrm{Q}(\text { inner })+\left(2 \mathrm{H}^{+}\right)_{\text {in }} \rightarrow 2 \mathrm{Q}(\text { outer })+\left(2 \mathrm{e}^{-}\right)_{\text {out }} \\
+\left(4 \mathrm{H}^{+}\right)_{\text {out }}+\mathrm{QH}_{2}(\text { inner })
\end{gathered}
$$

There are two cycles in series where two separate $\mathrm{QH}_{2}$ (outer) enter the protein, to pump $\left(4 \mathrm{H}^{+}+2 \mathrm{e}^{-}\right)$out, reduce two oxidized cytochrome $c$ (Cytc) by $1 \mathrm{e}^{-}$each, and where $\mathrm{Q}$ (inner) picks up $2 \mathrm{e}^{-}$total from two cycles of $\mathrm{QH}_{2}$ (outer), and $2 \mathrm{H}_{\text {in }}{ }^{+}$from the inside ( $\mathrm{n}$ side, negative $(-)$ ) of the membrane. Outer means near the $\mathrm{Q}_{\mathrm{o}}$ binding site within the protein, toward the positive outer side of the membrane ( $\mathrm{p}$ side), while inner means near the $\mathrm{Q}_{\mathrm{i}}$ binding site within the protein, near the negative inner side of the membrane ( $\mathrm{n}$ side).

$$
\begin{gathered}
\text { (Cycle 1): } \mathrm{QH}_{2}(\text { outer })+\mathrm{Q}(\text { inner }) \rightarrow \mathrm{Q}(\text { outer })+\left(2 \mathrm{H}^{+}\right)_{\text {out }} \\
+\mathrm{Q}^{\bullet-}(\text { inner })+\left(1 \mathrm{e}^{-}\right)_{\text {out }}
\end{gathered}
$$

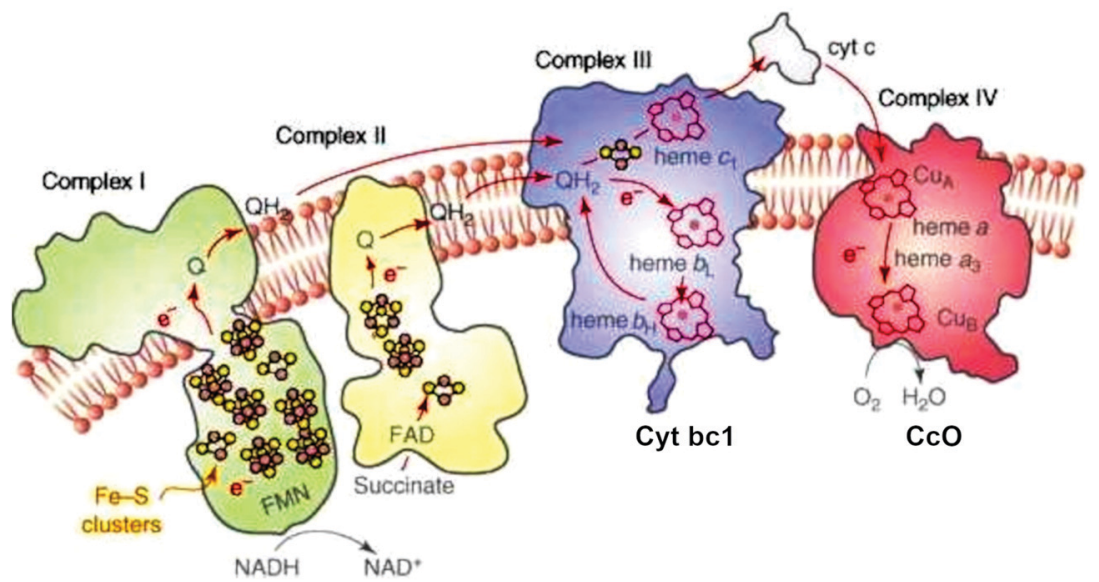

Fig. 1 Schematic of the four integral membrane protein complexes I-IV in the electron transport chain in mitochondria. Reprint with permission from Fig. 1 of ref. 13, copyright $(2008$ Elsevier. 
(Cycle 2): $\mathrm{QH}_{2}$ (outer) $+\mathrm{Q}^{\bullet-}$ (inner) $+2 \mathrm{H}_{\mathrm{in}}{ }^{+} \rightarrow \mathrm{Q}$ (outer)

$$
+\mathrm{QH}_{2}(\text { inner })+\left(2 \mathrm{H}^{+}\right)_{\text {out }}+\left(1 \mathrm{e}^{-}\right)_{\text {out }}
$$

The one Full Cycle (eqn (1)) is the sum of the two asymmetric Cycles 1 and 2 depicted below it. The molecule $\mathrm{Q}^{\bullet-}$ (inner) is the semiquinone radical anion that is a common intermediate linking these cycles. Although it is not in the cycles summarized above, $\mathrm{Q}^{\bullet-}$ (outer) is an unstable intermediate which facilitates the bifurcation of electron flow via heme $b_{\mathrm{L}}$. It is a product of the $\mathrm{QH}_{2}$ (outer) oxidation and deprotonation which occurs through the interaction with the Rieske $\mathrm{Fe}_{2} \mathrm{~S}_{2}$ cluster protein.

Fig. 2 depicts the electron transfers in more detail, but not the proton paths. The figure is schematic, and does not show the major conformational shift of the $\mathrm{Fe}_{2} \mathrm{~S}_{2}$ head group moving to dock with the cytochrome $c_{1}$ binding site. ${ }^{16-19}$

Anticipating our later discussion of $\mathrm{CcO}$, the mechanism of $\mathrm{C} c \mathrm{O}$ differs from that of Cyt $b c_{1}$ in a number of important ways. In Cyt $b c_{1}$, there is an internal mobile carrier of electrons and protons, $\mathrm{QH}_{2}$, which can move both within the membrane and within the protein forming two pools and having two binding sites labelled $\mathrm{Q}_{\mathrm{o}}$ and $\mathrm{Q}_{\mathrm{i}}$, for electron and proton transfer. There is a bifurcation (splitting) of electron transfer pathways between an upper pathway, and a lower pathway, which occurs near $\mathrm{Q}_{\mathrm{o}}$. As mentioned before, there is extensive mobility of the iron-sulfur fragment subunit. By contrast, in $\mathrm{CcO}$, there are no mobile carrier molecules for electrons or protons; all electron and proton transfers are through the protein and water network, and all mobility involves either water or protein sidechains and backbone movements. The conformational changes are smaller, where present. The electron transfer path starts with $1 \mathrm{e}^{-}$transfer from cytochrome $c$, which was reduced by Cyt $b c_{1}$. The subsequent electron transfer pathway is unidirectional, forming an approximate $\mathrm{L}$ shaped pathway from the $\mathrm{Cu}_{\mathrm{A}}$ site (a copper-dimer complex) to heme $a$ (or heme $b$ ) Fe to the heme $a_{3} \mathrm{Fe}$, and then terminating in the $\mathrm{Cu}_{\mathrm{B}}$ site. In $\mathrm{CcO}$ 's, there is a splitting in proton

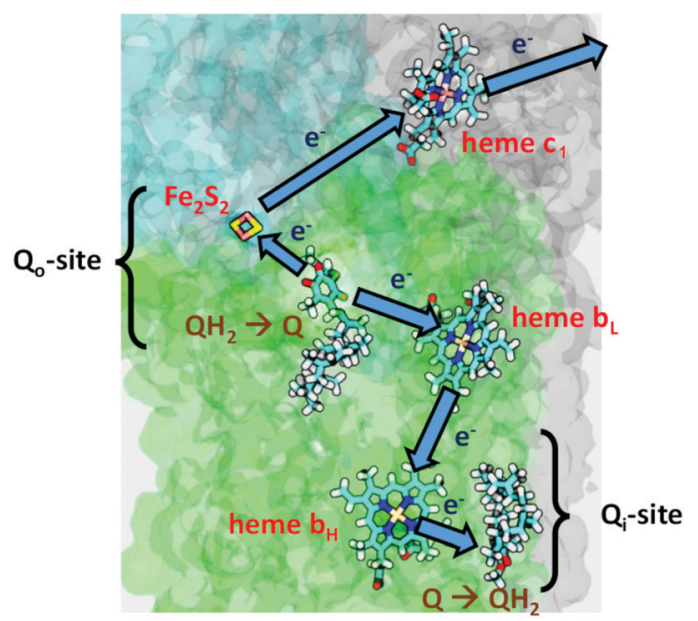

Fig. 2 Metal centers and electron transfers in Cyt $b c_{1}$ (Complex III). Reprint with permission from figure in https://quantbiolab.com/research/ superoxide-production-in-the-bc1-complex, copyright(C) 2020 Ilia Solov'yov and Peter Husen, QuantBio. pathways, which is, in part, a consequence of the difference between the so-called chemical protons, which react with electrons and bound oxygen species to finally produce water, and the pathways of pumped protons. There are also significant differences between the two families of $\mathrm{CcO}$, the A-Family versus the B-Family.

\subsection{Cytochrome $c$ oxidases-similarities in the catalytic cycle, differences in the proton pumping and reaction pathways of $b_{3}$ (B-Family) vs. $a a_{3}$ (A-Family)}

In Fig. 3, we present a structural map of the overall path of reactants and products for the $b a_{3}$ type (B-Family) of CcOs, specifically for the protein from $T t^{14,20-23}$ The heme $b$ and its $\mathrm{Fe}_{\mathrm{b}}$ is not seen in Fig. 3, since it lies behind the dinuclear center $\mathrm{Cu}_{\mathrm{B}}-\mathrm{Fe}_{\mathrm{a}_{3}}$-heme in this perspective. The positioning of heme $a$ in $a a_{3} \mathrm{CcO}$ is similar.

The mechanism for the chemical reaction

$$
\mathrm{O}_{2}+4 \mathrm{e}^{-}+4 \mathrm{H}_{\mathrm{in}}^{+} \rightarrow 2 \mathrm{H}_{2} \mathrm{O}
$$

is similar for both families, but the proton pumping input and exit pathways, and the water exit pathways are different. One should note that the proton input pathway (from the bottom of the figure upward) is opposite to that of the electron $\left(\mathrm{e}_{\mathrm{in}}{ }^{-}\right)$ entry, from the top, originating from reduced cytochrome $c$. (Fig. 3). The molecular oxygen $\left(\mathrm{O}_{2}\right)$ is more hydrophobic and enters the protein from the membrane via a fairly hydrophobic channel. After the pumped protons are included, the overall equation becomes

$$
\mathrm{O}_{2}+4 \mathrm{e}^{-}+(4+n) \mathrm{H}_{\mathrm{in}}^{+} \rightarrow 2 \mathrm{H}_{2} \mathrm{O}+n \mathrm{H}_{\text {out }}^{+}
$$

where $n=4$ (approximately, in the $a a_{3}$ type), and $n=2$ to 4 in the $b a_{3}$ type (as found for $T t$ ). ${ }^{25}$ Current experimental evidence is consistent with less efficient pumping pathways in $T t b a_{3}$, but still with very significant pumping. ${ }^{26}$

Differences in proton pathways between $a a_{3}$ Class $^{27-32}$ (in mitochondria and in aerobic bacteria) versus $b a_{3}$ Class $^{14,20-23}$ (in other aerobic bacteria) are depicted in Fig. 4, showing these protein structures with the different proton paths superimposed, D and $\mathrm{K}$ Path in $a a_{3}$, versus $\mathrm{K}_{\mathrm{B}}$ path, also called the

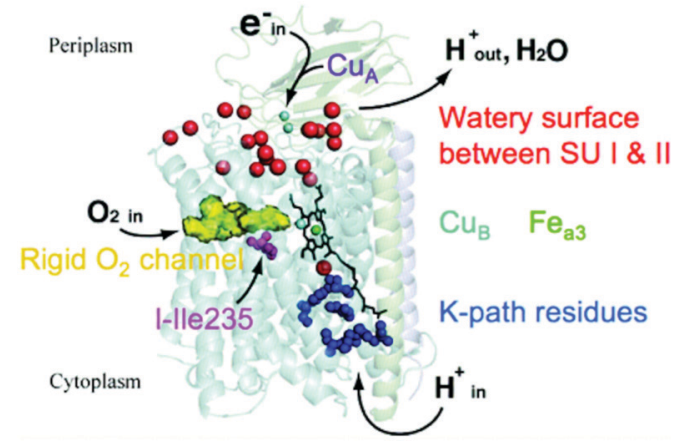

Fig. 3 Schematic of cytochrome $b a_{3}$ with noted functionalities. SU is subunit. Reprint with permission from Fig. 1 of ref. 24, https://pubs.acs.org/ doi/10.1021/ic500363h, copyright (C) 2014 American Chemical Society (further permissions for reusing this figure should be directed to the ACS). 


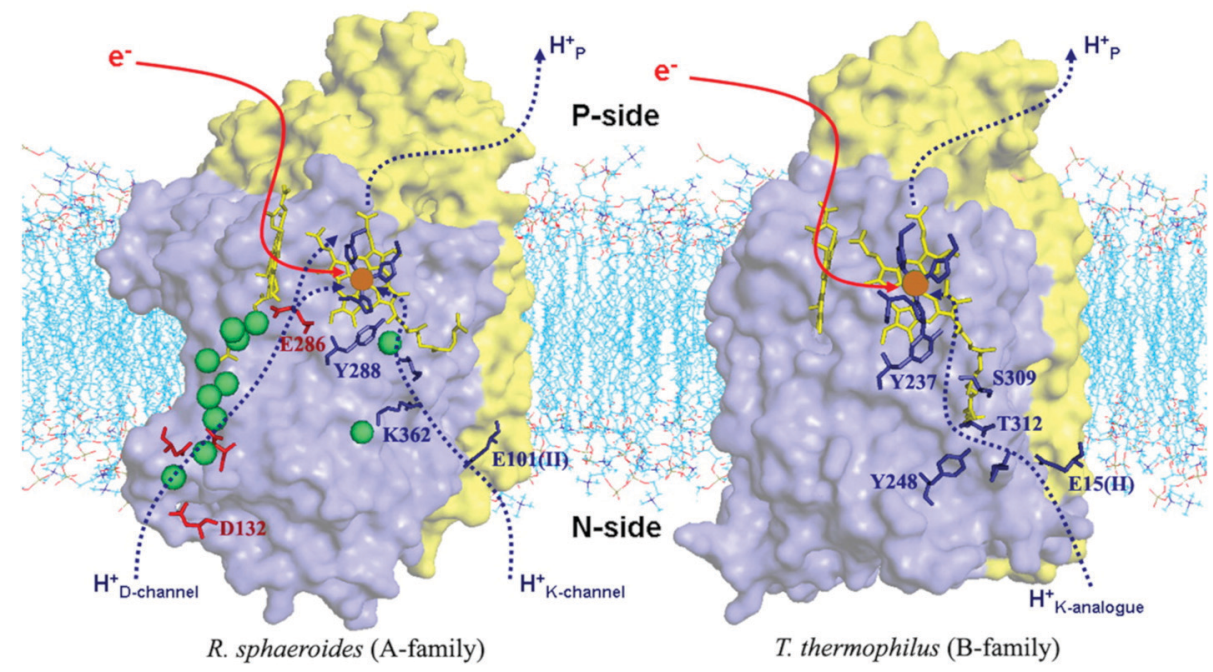

Fig. 4 Comparison of the proton delivery pathways for the A- and B-types CcO's. Reprint with permission from Fig. 3 of ref. 33, H. Y. Chang, et al. 2009.

$\mathrm{K}$ analogue path, in $b a_{3}$. The different subunits are shown in purple (Subunit I) and yellow (Subunit II). The K-input path in $a a_{3}$ (Rhodobacter sphaeroides) $^{28}$ is named for a lysine (K362) along that pathway. In $T t b a_{3}$, there is no similar structural lysine present in the $K_{\mathrm{B}}$ pathway, although there are other similar features, like the glutamic acid at the entrance, and the proton pathway exit point at a special tyrosine (Y288 in $a a_{3}$ and Y237 in $b a_{3}$ ). A more dramatic difference is the presence of a hydrophilic pathway with a line of waters (green) and a number of hydrophilic or charged residue sidechains in $a a_{3}$ from $R$. sphaeroides, in contrast to the absence of this pathway in $b a_{3}$ from $T t$. Also, the position of the important and often charged glutamic acid (E286) in $a a_{3}$ (R. sphaeroides) (Fig. 4) is structurally fairly homologous to that of the nonpolar isoleucine (I-Ile235) in $b a_{3}$ (Tt) (Fig. 3).

There is value in performing some simple bookkeeping analysis of differences in proton transport pathways in the different forms of $\mathrm{C} c \mathrm{O}, a a_{3}$ Type $v s . b a_{3}$ Type. First, we show a simple schematic Fig. 5 of the electrochemical potential difference (mainly a difference in the electrostatic potential) across the membrane. This is useful for clarity of language, and to show directionality of the potential across the membrane. The inside of the membrane is the $\mathrm{n}$ side (negative potential, -) while the outside is the $\mathrm{p}$ side (positive, + ). Referring back to Fig. 3 and eqn (4) and (5), both the chemical reaction, where the electrons and protons react and combine with $\mathrm{O}_{2}$ (eqn (4)), and the proton pumping (eqn (5)) contribute proportionately

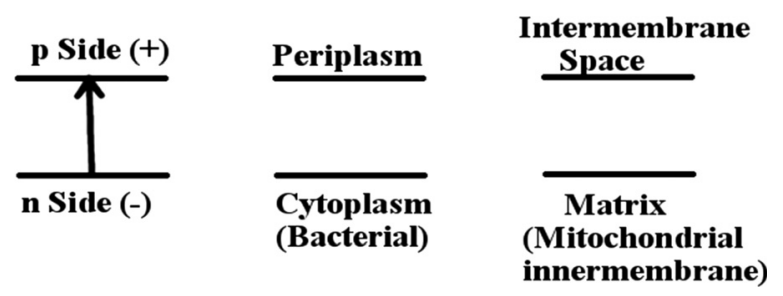

Fig. 5 The Electrochemical potential gradient across the membrane. (ratio $4: n$ charges) to the overall electrostatic potential (proportional to $(4+n)$ charges translocated). The reacting protons are called the Chemical (C) protons while the protons that are pumped are the Vector (V) protons.

Table 1 shows the different sources of protons for chemical reaction (C) versus protons shuttled into the pumping pathways (V). This is a condensation of observations based on electrometry and kinetics with and without ionophores on lipid vesicles with embedded proteins, and also utilizing mutagenesis to sort out proton transfer pathways. Clearly, large differences exist here between $a a_{3}$ type and $b a_{3}$ type. The $b a_{3}$ type has only one type of pathway in (K Path), which must account for both the Chemical protons entry into the reaction area (called the "reaction chamber"), and for the Vector protons to be pumped. There must be a bifurcation point (or region), where these pathways split. By contrast, the $a a_{3}$ type has two different paths in, $\mathrm{K}$ and $\mathrm{D}$. The $\mathrm{K}$ path analogue in $b a_{3}$ must do all the work of supplying both the 4 Chemical and 2 to 4 Vector protons. By contrast, the experimental evidence available indicates that the $\mathrm{K}$ path makes a smaller ( 2 proton) contribution to the overall chemical reaction, and none at all to the proton pumping in $a a_{3}$. In $a a_{3}$, the mechanism of the $\mathrm{D}$ pathway remains a matter of controversy. Further, in the mitochondrial protein, as found in eukaryotes, there is also a proposed $\mathrm{H}$ pathway, which may do some or all of the proton pumping in place of the $\mathrm{D}$ path in $a a_{3}$ type bacteria.

Table 1 Proton transport pathways in $\mathrm{CcO}$ : differences in proton channels

\begin{tabular}{|c|c|c|c|}
\hline Types & Chemical (C) & Vector (V) & Total over paths \\
\hline \multicolumn{4}{|c|}{$a a_{3}$ Type (bacterial and mitochondrial) } \\
\hline $\mathrm{K}$ path & 2 & 0 & 2 \\
\hline D path & 2 & 4 & 6 \\
\hline All paths & 4 & 4 & 8 \\
\hline \multicolumn{4}{|c|}{$b a_{3}$ Type (bacterial) } \\
\hline $\mathrm{K}$ path & 4 & $2-4$ & $6-8$ \\
\hline D path & 0 & 0 & 0 \\
\hline All paths & 4 & $2-4$ & $6-8$ \\
\hline
\end{tabular}




\subsection{Distinctive features of $b a_{3}$ in spectroscopy and kinetics}

For our purposes, it will be sufficient to explore some aspects of the chemical catalytic reaction cycle pathways, and potential mechanisms of proton pumping in the $b a_{3}$ type from $T t$, and to draw some comparisons and contrasts with $a a_{3}$ type $\mathrm{CcO}$ 's. In addition to the greater simplicity inherent in having all protons come in through the $\mathrm{K}$ pathway, there is a practical experimental advantage in tracing the reaction kinetics. In both $a a_{3}$ and $b a_{3}$ types, the electron pathway proceeds by $1 \mathrm{e}^{-}$ transfer from cytochrome $c$ (reduced, $\mathrm{Fe}^{2+}$, Cyt $c$ ), first to the $\mathrm{Cu}_{\mathrm{A}}$ Complex (containing a 2Cu dimer), and then to an Fe heme $b$ (in $b a_{3}$ ) or heme $a$ (in $a a_{3}$ ) and on to the dinuclear (DNC) (also called binuclear BNC) Complex, containing an $\mathrm{Fe}_{\mathrm{a} 3}$ heme closely associated with a $\mathrm{Cu}_{\mathrm{B}}-(\mathrm{His})_{3}$ unit. The Fe heme $b$ versus Fe heme $a_{3}$ difference makes it easier to distinguish by optical difference spectroscopy between reduction of $\mathrm{Fe}_{\mathrm{b}}$ versus $\mathrm{Fe}_{\mathrm{a} 3}$, while these bands are overlapping in $\mathrm{Fe}_{\mathrm{a}}$ versus $\mathrm{Fe}_{\mathrm{a} 3}$.

\subsection{Catalytic reaction cycle of $\mathrm{CcO}$}

The catalytic reaction cycle of the Dinuclear Complex (DNC) is depicted in Fig. 6. We include important intermediate states that have been identified spectroscopically as well as others that have been proposed linking observed states. ${ }^{34}$ To explore this cycle, we begin with State $\mathbf{R}$, the reduced state, where $\mathrm{Fe}_{\mathrm{a} 3}$ and $\mathrm{Cu}_{\mathrm{B}}$ have respective oxidation states, $\mathrm{Fe}^{2+}$ and $\mathrm{Cu}^{+}$. For the entire $\mathrm{CcO}$ protein to be in the fully reduced state, the other metal centers also must be reduced. For $\mathrm{Cu}_{\mathrm{A}}$, the reduced copper dimer state is then $\mathrm{Cu}^{+}-\mathrm{Cu}^{+}$. The corresponding oxidized state is the unusual delocalized mixed valence dimer, $\mathrm{Cu}^{1.5+}$ $\mathrm{Cu}^{1.5+}$. The other mononuclear heme Fe center (either heme $b$ or heme $a$ depending on $\mathrm{CcO}$ type) has reduced state $\mathrm{Fe}^{2+}$ and is low spin $S=0$. Both $\mathrm{Cu}_{\mathrm{A}}$ and the mononuclear Fe are $1 \mathrm{e}^{-}$donors to the DNC, so there is a net of 4 electrons available to carry out the catalytic $4 \mathrm{e}^{-}$reduction of $\mathrm{O}_{2}$ to $2 \mathrm{H}_{2} \mathrm{O}$ in eqn (4) (or eqn (5)). We will refer to the mononuclear heme $\mathrm{Fe}$ center and $\mathrm{Cu}_{\mathrm{A}}$ pair as $\mathrm{Fe} / \mathrm{Cu}_{\mathrm{A}}$. The reaction cycle commences by coordination of $\mathrm{O}_{2}$ to $\mathrm{Fe}_{\mathrm{a} 3}$ to form the adduct state $\mathbf{A}$. The cycle then progresses quickly through the proposed Peroxo and Hydroperoxo states to the experimentally identified states $\mathbf{P}_{\mathbf{M}} / \mathbf{P}_{\mathbf{R}}$ and further to state $\mathbf{F} . \mathrm{O}_{2}$ has already been reduced by four electrons in states $\mathbf{P}_{\mathbf{M}} / \mathbf{P}_{\mathbf{R}}$, with three electrons provided by $\mathrm{Fe}_{\mathrm{a}}$ and $\mathrm{Cu}_{\mathrm{B}}$ and one electron provided by the special tyrosine in state $\mathbf{P}_{\mathbf{M}}$, while one electron has been replenished from $\mathrm{Fe} / \mathrm{Cu}_{\mathrm{A}}$ in state $\mathbf{P}_{\mathbf{R}}$. One chemical proton has been taken up at this point and uptake of a second chemical proton leads to state $\mathbf{F}$. The subsequent reduction of the heme $\mathrm{a}_{3}$ ferryl-oxo complex via another electron from $\mathrm{Fe} / \mathrm{Cu}_{\mathrm{A}}$ and uptake of another proton is significantly slower and leads to active cycling oxidized state $\mathbf{O}_{\mathbf{H}}$ via the postulated intermediate state $\mathbf{F}_{\mathbf{H}}$. In summary, at this point, consumption of the 4 available electrons to reduce $\mathrm{O}_{2}$ results in the active cycling oxidized State $\mathbf{O}_{\mathbf{H}}$. To continue cycling, two electrons must be delivered from Cytc to the DNC to reduce $\mathrm{Fe}_{\mathrm{a} 3}$ and $\mathrm{Cu}_{\mathrm{B}}$ transiting via $\mathrm{Cu}_{\mathrm{A}} / \mathrm{Fe}$, and soon after two more electrons total from Cytc are needed at $\mathrm{Fe} / \mathrm{Cu}_{\mathrm{A}}$ to regenerate the fully reduced State $\mathbf{R}$. Up to 4 vectorial protons are pumped across the membrane during the reaction cycle. The reaction cycle intermediates observed spectroscopically were characterized by optical difference



Fig. 6 Feasible intermediate states of the DNC in the catalytic cycle, in which $\mathbf{A}, \mathbf{P}_{\mathbf{M}} / \mathbf{P}_{\mathbf{R}}, \mathbf{F}$, and $\mathbf{O}_{\mathbf{H}}$ were identified by resonance Raman experiments on A-type oxidases, ${ }^{37-52}$ and their DNC's are likely in the forms presented above. Although the Peroxo, Hydroperoxo, and $\mathbf{F}_{\mathbf{H}}$ states (drawn in red frames) were not observed experimentally, they may exist for a short time. Tyr is the special Y288 in aas and Y237 in ba3. 
spectroscopy $^{35}$ and by Resonance Raman (RR) spectroscopy, ${ }^{36}$ but the detailed active site structures were only partly established this way. In the figure, the kinetic rate constants were taken from Einarsdottir's kinetics study using optical difference spectroscopy on the $b a_{3}$ form of $\mathrm{CcO}$ from $T t,{ }^{35}$ while the $\mathrm{RR}$ frequencies presented are for $\mathrm{Fe}-\mathrm{O}$ stretch vibrations for $a a_{3}$ type from bovine mitochondria. ${ }^{37-52}$ For $b a_{3}$, the corresponding RR spectra have not been done, but the catalytic mechanism and intermediates should be similar. The kinetics of $b a_{3}$ are known to be different in detail from that in $a a_{3}$ bacterial proteins and mitochondrial proteins by optical difference spectroscopy. One main difference is that the $\mathrm{O}_{2}$ binding affinity and rate constant are higher in $b a_{3}$ than $a a_{3}$. For proton transfers, the redox, oxygen binding species, and protonation states of intermediates are clearer than the detailed sequence and timing of pumping events, which also differ between $b a_{3}$ and $a a_{3}{ }^{35}$ The mechanisms and reaction energetics (and kinetics) of proton transfer both within the catalytic cycle and for proton pumping have considerable uncertainties.

In Table 2, we summarize known mechanisms for proton and electron transport in redox active proteins. Since both protons and electrons are quantum objects, both can exhibit tunneling through proteins by covalent pathways, by hydrogen bonded pathways, and also through space, the last with much more difficulty. The ranges quoted reflect the shorter tunneling range of protons, which are about 1800 times as massive as electrons. This tunneling is through barriers, but there are also adiabatic (bonded) pathways for electrons, and normal barrier transits for proton transfers. Both electrons and protons can be carried on mobile carriers like ubiquinone, and protons can be transferred by movement and protonation/deprotonation of amino acid side chains, or carried on water as $\mathrm{H}_{3} \mathrm{O}^{+}$or $\mathrm{OH}^{-}$. Further, chains of waters and amino acid sidechains can perform effective fast long range proton transfer by concerted or partly coordinated proton transfers along a hydrogen bonded chain, as first proposed by Grotthuss. ${ }^{53}$ The more concerted form of this process requires a very ordered chain of H-bonded units, and a set of low barriers that can be only imperfectly attained in most biological systems. All of these different mechanisms need to be considered in redox driven proton pumps like $\mathrm{CcO}$ and Cytochrome $b c_{1}$.

\section{DFT methods, directions, and applications}

\subsection{DFT electronic structure and geometry optimization}

The starting geometries for electronic and geometry optimization for the DNC intermediate states are based on the $b a_{3}$ $\mathrm{CcO}$ X-ray crystal structure $3 \mathrm{~S} \mathrm{G}^{14}$ for the "resting oxidized as-isolated" state. ${ }^{24,54-60}$ These atom arrangements and geometries are altered to those proposed for the various states of the catalytic cycle based on what is known from spectroscopies and kinetics, with subsequent geometry optimization and further exploration of alternative structures. The geometry optimizations are performed using the $\mathrm{ADF}^{61-63}$ codes with the spin-polarized broken-symmetry method. ${ }^{64-66}$ Different DFT functionals like PW91, B3LYP, B3LYP*, OPBE, and OLYP have been tested in our earlier work (see Section 3.9). ${ }^{24,34}$ While the OLYP-D3-BJ exchange-correlation potential with dispersion correction (D3-BJ force field) ${ }^{67}$ has been used in our recent studies, ${ }^{58-60}$ together with the triple- $\xi$-polarization (TZP) Slater type basis sets on the metals, and DZP (double- $\xi$-polarization) on all other atoms, and with the COSMO ${ }^{68-71}$ solvation model for the outer environment with dielectric constant $(\varepsilon=18.5)$, reflecting considerable polarity as found in the remaining protein complex and solvent outside the quantum cluster region. For some states of the catalytic cycle in our vibrational frequency calculations, ${ }^{59}$ we have added energy corrections for spin-projection effects using the Yamaguchi equation, ${ }^{72-74}$ but we have not tried to incorporate these into our very recent resting as-isolated State $\mathbf{O}$ calculations; ${ }^{60}$ we think that effects there will prove to be small, since the spin coupling between $\mathrm{Fe}^{2+, 3+}$ and $\mathrm{Cu}^{2+}$ in those geometries is small.

Fig. 7 gives our geometry optimized quantum cluster model for State $\mathbf{A},{ }^{59}$ the ferric-superoxide complex of the DNC, formed upon binding of molecular oxygen to the ferrous $\mathrm{Fe}^{2+}$ in State $\mathbf{R}$ which can be compared to the schematic form in Fig. 6. Notice also that $\mathrm{Cu}$ is in the reduced cuprous redox state, $\mathrm{Cu}^{+}$, which affects the subsequent reaction path.

As already suggested in Fig. 6, for a good representation of the catalytic cycle, different binding states of oxygen species, different $\mathrm{Fe}$ and $\mathrm{Cu}$ redox states in the DNC, different protonation states (also tautomeric states), and different water locations must be evaluated. The presence of water as both a medium useful for stabilization of states and transit, and also as a reaction product introduces further essential complexities. As depicted in Fig. 7, Tyr237 in $T t b a_{3}$ (and the structurally homologous Tyr288 in $a a_{3}$ enzymes) is special; the Tyr phenol is covalently linked to the His233 sidechain ring via a $\mathrm{C}-\mathrm{N}$ covalent bond, and the His ring is a ligand to $\mathrm{Cu}_{\mathrm{B}}$. This linkage is universal in $a a_{3}$ and $b a_{3} \mathrm{CcO}$ 's and unique from all other metalloenzymes. At this point, we reflect also on the combination of different redox states and protonation states accessible for amino acid sidechains in $\mathrm{CcO}$. For the special tyrosine, there are three states Tyr- $\mathrm{O}^{\bullet}$ (neutral radical), Tyr- $\mathrm{O}^{-}$(anion), and Tyr-OH (neutral protonated). The Tyr-O is also the end of

Table 2 Modes of proton mobility and electron mobility

The variety of electron and proton transport in proteins and membranes

- Electron tunneling - max range about 11-14 ̊

- Electron transport on mobile carrier
- Proton tunneling - max range about $1 \mathrm{~A}$

- Proton transport on mobile carrier

- Proton transport on amino acid sidechain

- Proton transport by diffusion on water $\left(\mathrm{H}_{2} \mathrm{O}\right.$ as carrier)

- Grotthuss process ${ }^{53}$ - fast proton transfer along chains of water molecules, also in combination with amino acid sidechains (Bucket Brigade mechanism) 


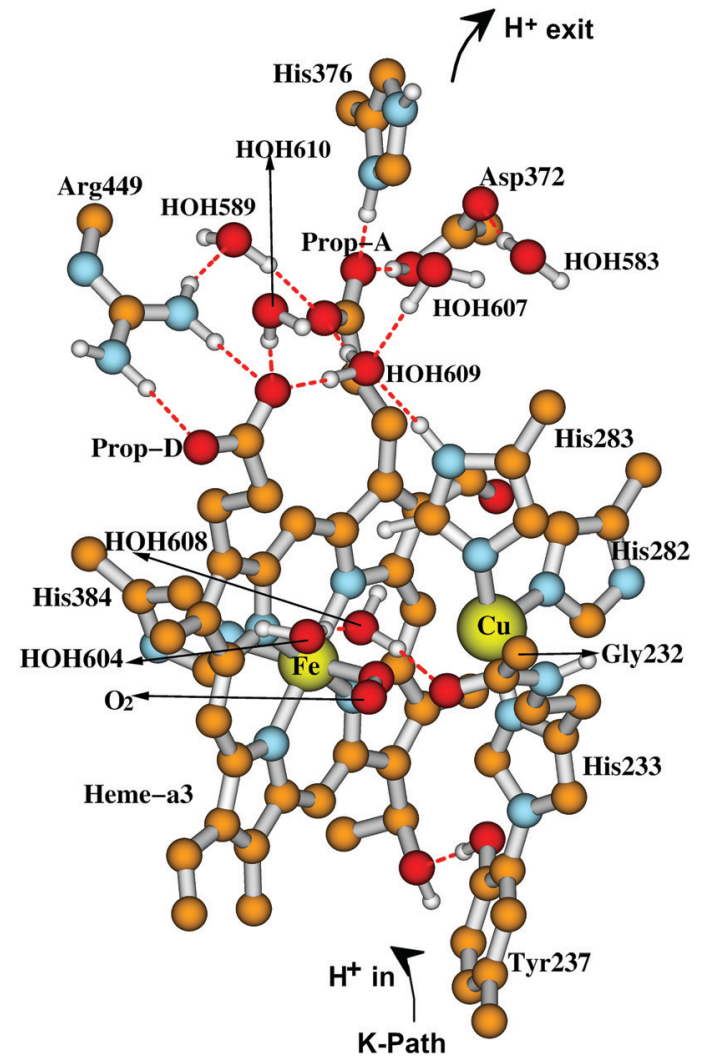

Fig. 7 Our quantum cluster model for state $\mathbf{A}$ of the DNC, built from the $\mathrm{X}$-ray crystal structure $3 \mathrm{~S} 8 \mathrm{G}$ of $\mathrm{ba}_{3} \mathrm{CcO}$ from $\mathrm{Tt} .{ }^{14}$ For more visibility, some apolar or link $\mathrm{H}$ atoms are not shown on the picture. Taken with permission from Fig. 3 of ref. 59, copyright (C) 2019 American Chemical Society.

the K pathway for protons. For other residues, we will see later that there is a potentially redox active tryptophan with states Trp (neutral) and $\operatorname{Trp}^{\bullet+}$ (radical cation). Histidine is usually considered to have three states His(neutral, protonated at $\delta$ ), His(neutral, protonated at $\varepsilon$ ), and $\mathrm{His}^{+}$(cation, protonated at both). However, when bonded to a high oxidation state metal $\mathrm{Cu}^{2+}$, the $\mathrm{His}^{-}$(anion) state is also possible.

Turning now to the $\mathrm{Fe}_{\mathrm{a} 3}$ sites, in addition to the relevant redox states $\mathrm{Fe}^{2+}, \mathrm{Fe}^{3+}, \mathrm{Fe}^{4+}$, there are different site spin states possible: high-spin (HS), intermediate-spin (IS), and low-spin (LS). For $\mathrm{Cu}_{\mathrm{B}}$, the redox states cycle between $\mathrm{Cu}^{+}$and $\mathrm{Cu}^{2+}$ and connect to the linked redox and protonation states of the special His-Tyr pair.

\subsection{Vibrational frequencies}

For vibrational frequency calculations,${ }^{59}$ we used two different complementary methods at the geometry optimized structures. ${ }^{61}$ From the original cluster model of about 200 atoms, we compute a partial Hessian (about 110 atoms) using analytic frequency calculations in the region surrounding the $\mathrm{FeCu}$ center, excluding atoms in the upper cluster region (Arg449, His376, Asp372, and four upper waters) plus two waters that are shifted up $\mathrm{HOH} 604$ and HOH608 in the intermediate states $\mathbf{F}, \mathbf{F}_{\mathbf{H}}$, and $\mathbf{O}_{\mathbf{H}}$. We have also done comparative calculations with the numerical mobile block Hessian method, ${ }^{75,76}$ where the residue sidechains in the upper region and nearby waters are treated as individual mobile blocks. Both methods yield very similar vibrational frequencies for $\mathrm{Fe}-\mathrm{O}$ stretching modes, and also for $\mathrm{O}-\mathrm{O}$ or $\mathrm{O}-\mathrm{Fe}-\mathrm{Por}$ bending modes.

\subsection{Recent DFT work on $b a_{3}$ in comparison with experimental spectroscopy (resonance Raman): $\mathrm{Fe}-\mathrm{O}$ and $\mathrm{O}-\mathrm{O}$ geometries versus stretch frequencies}

In Fig. 8, we report a graph comparing calculated versus experimentally observed Resonance Raman frequencies for $\mathrm{Fe}_{\mathrm{a} 3}-\mathrm{O}$ stretching frequencies over intermediate states of the catalytic cycle. ${ }^{59}$ In Fig. 9, we explore the accuracy of an old empirical correlation for bond lengths versus frequencies, called Badger's rule ${ }^{77}$ applied to examining Fe-O bond lengths versus stretch frequencies. We find that this correlation is very good and reliable based on our calculations. Also, Fig. 10 shows that the calculated $\mathrm{O}-\mathrm{O}$ stretch frequencies correlate very well, linearly, with the $\mathrm{O}-\mathrm{O}$ bond length; Fig. 11 shows that these same frequencies correlate similarly well with the calculated Mayer Bond Order. ${ }^{78}$ There are only a few structures in the

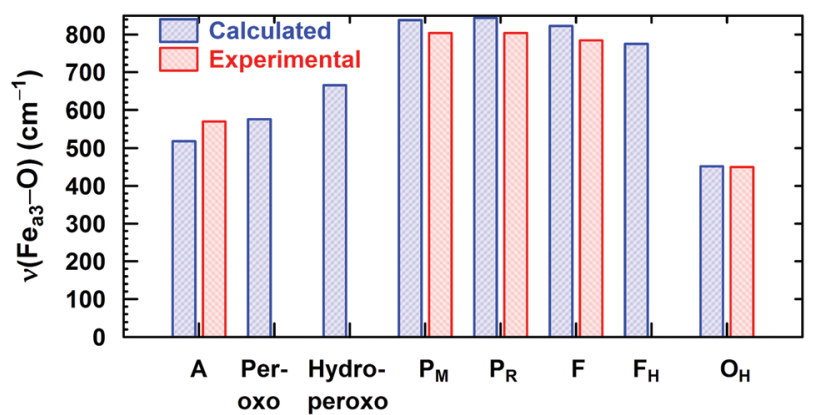

Fig. 8 Calculated vs. available experimental $\mathrm{Fe}_{a 3}-\mathrm{O}$ vibrational stretching modes for the DNC intermediate states. Reprinted with permission from ref. 59, copyright $(\mathbb{C} 2019$ American Chemical Society.



Fig. 9 Correlation between the calculated $\mathrm{Fe}_{\mathrm{a} 3}-\mathrm{O}$ bond lengths $\left(r_{\mathrm{Fe}-\mathrm{O}}, \AA\right)$ and the corresponding $\mathrm{Fe}_{\mathrm{a} 3}-\mathrm{O}$ stretch frequencies $\left(1 / \nu_{\mathrm{Fe}-\mathrm{O}} 2 / 3\right.$, based on Badger's rule) for the eight DNC state structures studied. ${ }^{59}$ Reprint with permission from Fig. 7 of ref. 59, copyright (C) 2019 American Chemical Society. 




Fig. 10 Correlation between the calculated $\mathrm{O}-\mathrm{O}$ stretching frequencies $\left(\nu(\mathrm{O}-\mathrm{O}), \mathrm{cm}^{-1}\right)$ and the $\mathrm{O}-\mathrm{O}$ bond lengths $\left(r_{\mathrm{O}-\mathrm{O}}, \AA\right)$. Taken with permission from Fig. 6 of ref. 59, copyright (C) 2019 American Chemical Society.

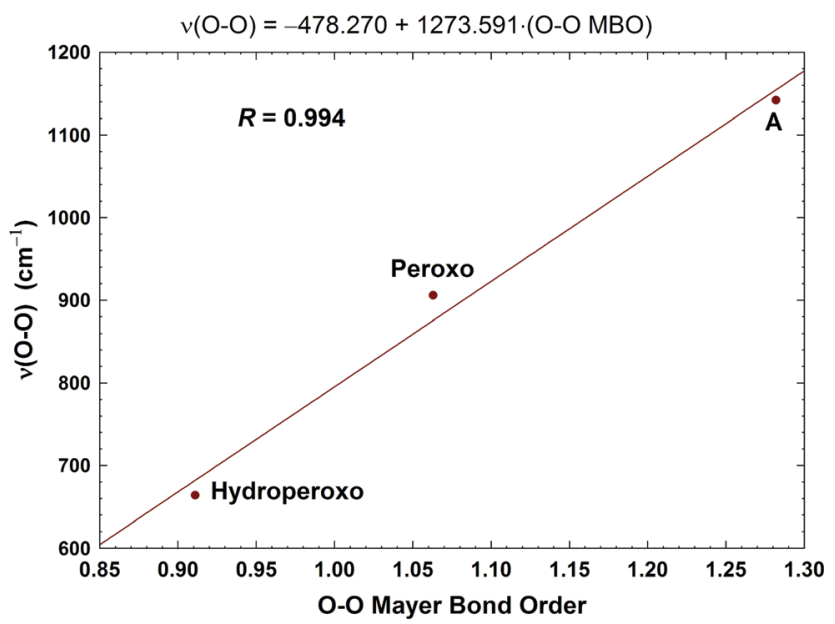

Fig. 11 Correlation between the calculated $\mathrm{O}-\mathrm{O}$ stretching frequencies $\left(\mathrm{cm}^{-1}\right)$ and the Mayer O-O bond orders (MBO). Taken with permission from Fig. 6 of ref. 59, copyright $(C) 2019$ American Chemical Society.

cycle which have intact $\mathrm{O}-\mathrm{O}$ bonds, but the frequencies for superoxide $\mathrm{O}-\mathrm{O}$ in State $\mathbf{A}$, and $\mathrm{O}-\mathrm{O}$ in our Peroxo structure match those in related synthetic systems ${ }^{79-82}$ very well (see the discussion below).

Starting from a map of the basic catalytic cycle (Fig. 6), we consider the changes in $\mathrm{Fe}-\mathrm{O}$ bonding, and $\mathrm{O}-\mathrm{O}$ bonding where present over the cycle. ${ }^{59}$ Beginning with the fully reduced State $\mathbf{R}$ ( $\mathrm{HS} \mathrm{Fe}^{2+}$ and $\mathrm{Cu}^{+}$), when molecular oxygen binds ( $\mathrm{O}_{2}$ triplet, $S=1$ spin state), the bound state is formally an iron-oxygen adduct (State $\mathbf{A}$ ), but the electronic structure is closer to that of ferric $\mathrm{LS} \mathrm{Fe}^{3+}$ bonded to superoxide radical anion $\mathrm{O}_{2}{ }^{\bullet-}$. The bonding represents a balance between a partial bond broken in $\mathrm{O}_{2}$, from loss of part of the $\mathrm{O}=\mathrm{O} \pi$ bond, and the energy gained from one electron transfer from $\mathrm{Fe}^{2+}$ to $\mathrm{O}=\mathrm{O}$, plus the bonding energy from the forming $\sigma-\pi$ hybrid to the $\mathrm{Fe}(3 \mathrm{~d})$ shell. The strong ligand field from $\mathrm{O}_{2}{ }^{-}$binding changes the $\mathrm{Fe}^{3+}$ spin state from $\mathrm{HS} \rightarrow$ LS, and this also affects the $\mathrm{Fe}-\mathrm{O}$ stretch frequency. The $\mathrm{O}_{2}$ binds in a bent end-on structure, and this description is very much like the bonding in oxymyoglobin (oxy-Mb). ${ }^{83,84}$ The calculated $\mathrm{Fe}-\mathrm{O}$ frequencies in oxy- $\mathrm{Mb}$ are similar to those predicted in State $\mathbf{A}$ of $\mathrm{CcO}$, and the experimental frequencies are also very similar between the two Fe metalloproteins $\left(\sim 570 \mathrm{~cm}^{-1}\right) .{ }^{37-44,85-87}$ The predicted $\mathrm{Fe}-\mathrm{O}$ frequencies are in both cases less than the experimental frequencies by about $10 \%\left(50 \mathrm{~cm}^{-1}\right)$ out of about $570 \mathrm{~cm}^{-1}$. This is the largest deviation in calculations from experiment for all Fe-O bonding species observed throughout the catalytic cycle. We also have excellent predictions for the $\mathrm{O}-\mathrm{O}$ bond frequency in State $\mathbf{A}$ of $\mathrm{CcO}$, but here the experimental data available are for synthetic porphyrin systems. ${ }^{79,88-91}$

After formation of State $\mathbf{A}$, one electron transfer from $\mathrm{Cu}^{+}$to $\mathrm{Fe}^{3+}$ bound superoxide leads to very fast steps that have not been directly seen either by optical difference spectroscopy or RR spectroscopy. We have calculated in sequence a Peroxo bridging state after $1 \mathrm{e}^{-}$transfer, and then a Hydroperoxo state following protonation. The Hydroperoxo state is probable, and the proton is thought to originate from the protonated Tyr237. For the Peroxo state, it is not evident if the bridging structure is formed before the following proton transfer occurs. In a structurally analogous synthetic $\mathrm{Fe}^{3+}-\mathrm{O}_{2}{ }^{2-}-\mathrm{Cu}^{2+}$ complex, the measured $\mathrm{O}-\mathrm{O}$ stretch frequency $\left(870 \mathrm{~cm}^{-1}\right)$ is close to the one we calculated (906 $\mathrm{cm}^{-1}, 4 \%$ deviation). ${ }^{82}$ However, in the $\mathrm{CcO}$ protein, the initial $\mathrm{O}$ atom coordination to $\mathrm{Cu}$ could be looser, and the $1 \mathrm{e}^{-}$and $1 \mathrm{H}^{+}$transfers may even occur concertedly. The proton position on the oxygen nearer the $\mathrm{Cu}^{2+}$ is needed for the next reaction steps. For the rapid cleavage of the $\mathrm{O}-\mathrm{O} \sigma$ bond, one electron is transferred from $\mathrm{Fe}^{3+}$ to make the ferryl-oxo, $\mathrm{Fe}^{4+}=\mathrm{O}^{2-}$, while the other electron can come either from the Tyr237 by through-bond electron transfer to make State $\mathbf{P}_{\mathbf{M}}$, or directly from the mononuclear heme $b \mathrm{Fe}^{2+}$ (equivalently from heme $a \mathrm{Fe}$ in $a a_{3}$ ) to produce State $\mathbf{P}_{\mathbf{R}}$. (If $\mathbf{P}_{\mathbf{M}}$, the Tyr ${ }^{\bullet}$ radical state, is generated first, the next electron transfer to make $\mathbf{P}_{\mathbf{R}}$ again comes from $\mathrm{Fe}_{\mathrm{b}}$ ). In State $\mathbf{P}_{\mathbf{R}}$, the bridge has the form of $\mathrm{Fe}^{4+}=\mathrm{O}^{2-}$ coordinated by a hydrogen bond to $\mathrm{OH}^{-}-\mathrm{Cu}^{2+}$. After the $\mathrm{OH}^{-}$is protonated, this changes to State $\mathbf{F}$, and the $\mathrm{Fe}-\mathrm{O}$ stretch frequency decreases by about $20 \mathrm{~cm}^{-1}$ in the experimental RR data from $804 \mathrm{~cm}^{-1}$ to $785 \mathrm{~cm}^{-1} \cdot{ }^{45,47-52,92}$ A similar frequency shift is found in the DFT calculations, from $844 \mathrm{~cm}^{-1}$ to $823 \mathrm{~cm}^{-1} \quad(5 \%$ deviation from experiment for the frequencies). ${ }^{59}$ There is a slight DFT calculated lengthening $(+0.01 \AA)$ of the $\mathrm{Fe}-\mathrm{O}$ bond, but it is probably more important that the $\mathrm{Fe}^{4+}=\mathrm{O}^{2-} \cdots \mathrm{H}_{2} \mathrm{O}-\mathrm{Cu}^{2+}$ hydrogen bond shortens (from $2.67 \AA$ to $2.52 \AA$, calculated), and strengthens with $\mathrm{H}_{2} \mathrm{O}-\mathrm{Cu}^{2+}$ coordination compared to $\mathrm{OH}^{-}-\mathrm{Cu}^{2+}$, consistent with a stronger electrostatic interaction. This shows that the $\mathrm{Fe}-\mathrm{O}$ stretch frequency can reflect moderate local interactions in addition to the direct $\mathrm{Fe}-\mathrm{O}$ bond length correlation.

The Fe-O vibrational frequency undergoes a major downshift (to $450 \mathrm{~cm}^{-1}$, experimental) ${ }^{50}$ when a $\left(1 \mathrm{e}^{-}, 1 \mathrm{H}^{+}\right)$addition to the active site $\left(1 \mathrm{e}^{-}\right.$coming from the heme $b \mathrm{Fe}$, and $1 \mathrm{H}^{+}$from the $\mathrm{K}$ pathway) produces the State $\mathbf{O}_{\mathbf{H}}$, which is the active oxidized state ready for further cycling. This corresponds to a much longer $\mathrm{Fe}^{3+}-\mathrm{O}$ bond. We calculate a nearly symmetric 
$\mathrm{Fe}^{3+}-\mathrm{OH}^{-}-\mathrm{Cu}^{2+}$ geometry, with $\mathrm{Fe}-\mathrm{O}, \mathrm{Cu}-\mathrm{O}$ distances of $1.98 \AA$ and $1.99 \AA$ found for $\mathrm{HS}-\mathrm{Fe}^{3+}$. The bridging $\mathrm{OH}^{-}$group is hydrogen bonded to a water molecule that lies outside the line between $\mathrm{Fe}-\mathrm{OH}^{-}-\mathrm{Cu}$, allowing the near symmetric bridge. With the OLYP-D3-BJ potential, the IS-Fe ${ }^{3+}$ state is calculated lower in energy than $\mathrm{HS}-\mathrm{Fe}^{3+}$ by $7 \mathrm{kcal} \mathrm{mol}^{-1}$, and has a very similar active site geometry (see Supporting information, Table S1 in Han Du, IC 2020). ${ }^{60}$

In this paper, ${ }^{60}$ we used a larger basis set TZP on all atoms. The geometries are similar to those with the smaller basis set. We very recently recalculated the $\mathbf{O}_{\mathbf{H}}\left(\mathrm{Fe}-\mathrm{OH}^{-}-\mathrm{Cu}\right)$ state vibrational frequencies. The $\mathrm{Fe}-\mathrm{O}$ frequencies decrease by about 25 to $30 \mathrm{~cm}^{-1}$. The $\mathrm{Fe}-\mathrm{O}$ stretch frequency is clearer in the $\mathrm{HS}_{-} \mathrm{Fe}^{3+}$ than in the IS-Fe ${ }^{3+}$ state, where there is more extensive mixing of $\mathrm{Fe}-\mathrm{O}$ stretching with $\mathrm{Fe}-\mathrm{O}$ bend modes and Fe-porphyrin modes. In both cases, the calculated frequencies are similar, for $\mathrm{HS}, \mathrm{Fe}-\mathrm{O}$ frequency $423 \mathrm{~cm}^{-1}$, and for IS, we identified a mode with some $\mathrm{Fe}-\mathrm{O}$ stretch character at $413 \mathrm{~cm}^{-1}$. In earlier experimental work, Rousseau ruled out the $\mathrm{LS} \mathrm{Fe}^{3+}-\mathrm{OH}^{-}$state because he expected a high $\mathrm{Fe}-\mathrm{O}$ stretch frequency. ${ }^{50}$ Our calculations further support this result, with calculated LS Fe-O distance of $1.88 \AA$, and a high calculated stretch frequency of $514 \mathrm{~cm}^{-1}$ (14\% deviation from exp.) for LS, versus (6\%) for HS, and ( $8 \%$ ) for IS. The LS state is also higher in energy than both the HS and IS states. Also, we wanted to evaluate whether a state of composition $\mathrm{Fe}^{\mathrm{HS}, 3+}-\mathrm{OH}^{-} \cdots \mathrm{H}_{2} \mathrm{O}-$ $\mathrm{Cu}^{2+}$ with a bridging hydroxyl-water hydrogen bond, and with the $\mathrm{H}_{2} \mathrm{O}$ coordinated to $\mathrm{Cu}^{2+}$ is feasible for State $\mathbf{O}_{\mathbf{H}}$, since it has a similar $\mathrm{Fe}-\mathrm{O}$ bond distance. Several $\mathrm{Fe}-\mathrm{O}-\mathrm{H}$ vibrational modes are obtained in the region $408-437 \mathrm{~cm}^{-1}$, still in good agreement with exp. $450 \mathrm{~cm}^{-1}$. However, the hydroxyl-water bridge state energetically lies well above the corresponding $\mathbf{O}_{\mathbf{H}}\left(\mathrm{Fe}-\mathrm{OH}^{-}-\mathrm{Cu}\right)$ structure, in which the bridging $\mathrm{OH}^{-}$has $\mathrm{H}$-bonding interaction with an outer water molecule (see ref. 60 and Supporting material). We have paid close attention to State $\mathbf{O}_{\mathbf{H}}$ because it is an essential oxidized state for continued cycling, and also because of the contrast with the resting oxidized state, which is the oxidized state structurally characterized by synchrotron or X-ray Free Electron Laser (XFEL) structures.

\subsection{The pathway from $P_{R} \rightarrow F \rightarrow O_{H}$}

While exploring the reaction pathway from $\mathbf{P}_{\mathbf{R}} \rightarrow \mathbf{F} \rightarrow \mathbf{O}_{\mathbf{H}}$, we found a probable proton pumping pathway using a water shift mechanism. ${ }^{58}$ Fig. 12 displays relevant structures before a shift up of a water dimer (abeled $\mathrm{HOH} 604, \mathrm{HOH} 608$ ) from a hydrogen bonding position to the $\mathrm{OH}^{-}\left(\right.$State $\mathbf{P}_{\mathbf{R}}$ ) or $\mathrm{H}_{2} \mathrm{O}$ (State $\mathbf{F}$ ) ligand on $\mathrm{Cu}_{\mathrm{B}}{ }^{2+}$ into the upper water pool adjacent to His376 (neutral or protonated cation). Fig. 13 presents a schematic of the entire reaction pathway from $\mathbf{P}_{\mathbf{R}} \rightarrow \mathbf{F} \rightarrow \mathbf{O}_{\mathbf{H}}$ including the initiation of the pumping process by proton loss from His $376-\mathrm{H}^{+}$. The important features of this detailed mechanism are: (1) proton transfers by $\mathrm{H}^{+}$uptake from the $\mathrm{K}$ path onto Tyr237 and from there to the $\mathrm{OH}^{-}-\mathrm{Cu}_{\mathrm{B}}{ }^{2+}$ are needed to allow the water dimer shift to occur;
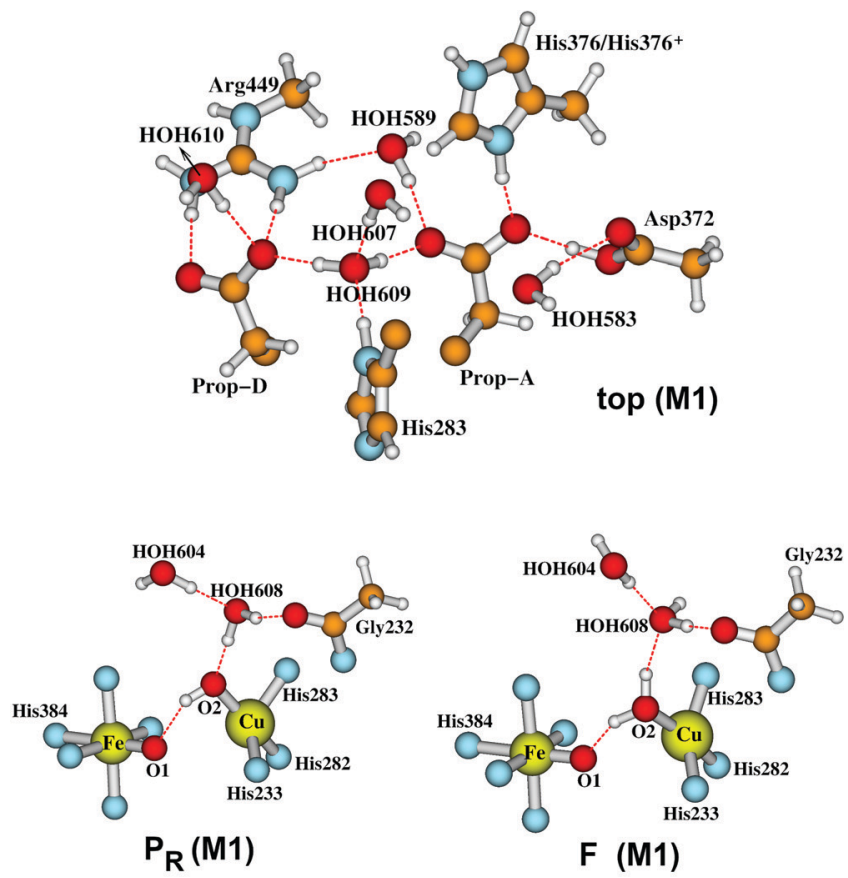
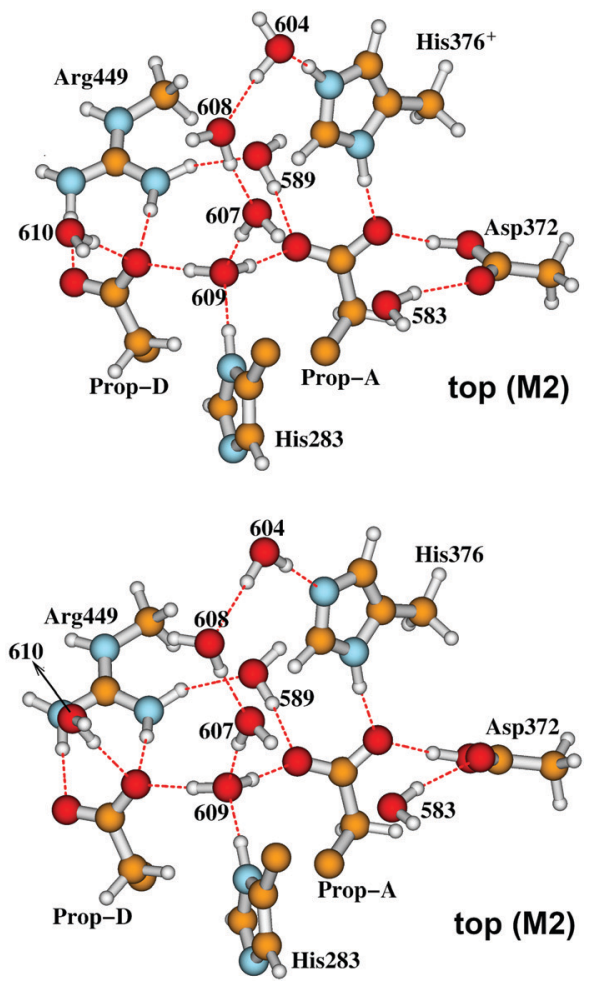

Fig. 12 In our Model 1 (M1), ${ }^{58}$ the two water molecules $\mathrm{HOH} 604$ and $\mathrm{HOH} 608$ are within the DNC as observed in the X-ray crystal structure $3 \mathrm{~S} 8 \mathrm{G} .{ }^{14}$ The size of our DNC model clusters are the same as state $\mathbf{A}$ shown in Fig. 7. A clearer view of the top portion of the cluster (top M1) and the central portions of states $\mathbf{P}_{\mathbf{R}}$ and $\mathbf{F}$ are given here. In Model 2 (M2), the two water molecules $\mathrm{HOH} 604$ and $\mathrm{HOH} 608$ are shifted to the upper part of the DNC to the positions as shown on the upper-right (top M2) for protonated His376- $\mathrm{H}^{+}$and lower-right (top M2) for neutral His376 cases. ${ }^{58}$ 




Fig. 13 Feasible proton uptake/pumping processes connecting with the movement of water molecules in the DNC during the $P_{R} \rightarrow F$ transition based on our current Models (M) 1-3 calculations. The $2 \mathrm{H}_{2} \mathrm{O}$ represents $\mathrm{HOH} 604$ and $\mathrm{HOH} 608$. In M1, the two water molecules are within the DNC H-bonded to the $\mathrm{OH}^{-}$or $\mathrm{H}_{2} \mathrm{O} \mathrm{Cu}{ }_{\mathrm{B}}{ }^{2+}$ ligands close to the positions observed in the X-ray crystal structure $358 \mathrm{G} .{ }^{14}$ In M2, the $2 \mathrm{H}_{2} \mathrm{O}$ are shifted to the upper water pool of the DNC. In M3, the water molecule that is a ligand of $\mathrm{Cu}_{\mathrm{B}}{ }^{2+}$ in $\mathrm{M} 2$, now dissociates from $\mathrm{Cu}_{\mathrm{B}}{ }^{2+}$ but still has $\mathrm{H}$-bonding interaction with the $\mathrm{Fe}_{a 3}$-ligand $\mathrm{O}^{2-}$. Figure is adapted with permission from Fig. 4 of ref. 58, copyright (C) 2018 American Chemical Society.

(2) there is then an energetically favorable proton uptake by Tyr237 $7^{-}$, in the transition $\mathrm{c} \rightarrow \mathrm{d}$; (3) both the $\mathrm{H}_{2} \mathrm{O}-\mathrm{Cu}_{\mathrm{B}}{ }^{2+}$ and neutral Tyr237 need to be present, and are energetically favored before the water dimer shift occurs with a small energy cost, calculated $\Delta G=+4.2 \mathrm{kcal} \mathrm{mol}^{-1}$. The calculated $\mathrm{p} K_{\mathrm{a}}$ shift of His $376^{+}$before and after the water dimer shift is large, from 12.2 to $6.5, \Delta \mathrm{p} K_{\mathrm{a}}=5.7$ equivalent to a relative $\Delta G=7.8 \mathrm{kcal} \mathrm{mol}^{-1}$. Following the reaction pathway from $\mathrm{d} \rightarrow \mathrm{e} \rightarrow \mathrm{f}$, after the proton loss from $\mathrm{H}_{376^{+}}$, a subsequent proton transfer from Tyr376 (neutral) is favorable. It is important that the Tyr237 (neutral, protonated) does not lose its proton by back leakage into the $\mathrm{K}$ pathway after the water shift, because that water shift also lowers the $\mathrm{p} K_{\mathrm{a}}$ of Tyr237 strongly, from $\mathrm{p} K_{\mathrm{a}}=11.0$ to 5.5 when His376 is protonated. A general problem of this type has been considered by other groups. Knapp and coworkers have proposed, based on electrostatics and dynamics modeling, that when the Tyr237 is protonated $(\mathrm{Y} 237-\mathrm{OH})$, the hydrogen bonded pathway (a Grotthuss type pathway) in the $\mathrm{K}$ path is broken so that backflow is inhibited. ${ }^{93}$ This appears reasonable as it stands, but there is considerably more to learn about the $\mathrm{K}$ path proton transfer mechanism both in $b a_{3}$ and $a a_{3}$ types of $\mathrm{CcO}$.

We have analyzed this water dimer shift mechanism further with additional modeling. We find that if in the state just before the water dimer shift (pre-shift states are called M1 states), we add $2\left(\mathrm{H}_{2} \mathrm{O}\right)$ to the upper water pool in our quantum cluster model and calculate the His $376^{+} \mathrm{p} K_{\mathrm{a}}$ for that (M1 + $\left.2 \mathrm{H}_{2} \mathrm{O}\right)$ state, the value is $\mathrm{p} K_{\mathrm{a}}=10.7$, about $1.5 \mathrm{pH}$ units below the corresponding M1 state discussed earlier, but still $4.2 \mathrm{pH}$ units higher than the corresponding $\mathrm{M} 2$ state (after the $2 \mathrm{H}_{2} \mathrm{O}$ shift, but with no net added waters). Our conclusion is that the descreening of the $\mathrm{H}_{2} \mathrm{O}-\mathrm{Cu}_{\mathrm{B}}{ }^{2+}$-(His) $)_{3}$ ligand group when the water dimer moves to the upper water pool is the primary effect causing a strong change in the His $376^{+} \mathrm{p} K_{\mathrm{a}}$. The Tyr237 (neutral protonated) and the $\mathrm{Fe}_{\mathrm{a} 3}{ }^{4+}=\mathrm{O}^{2-}$ are also descreened. Primarily, the descreening calculated at His $376^{+}$is a through space effect, while the effect on the Tyr237 $\mathrm{p} K_{\mathrm{a}}$ is a mixture of through bond and through space effects. We have focused on a water dimer shift for two reasons. First, given the initial structures (M1 states), moving a dimer into the upper water pool looked to be less disruptive of the hydrogen bond network. Further, we were intrigued by the possible connection to the expected net $\mathrm{H}_{2} \mathrm{O}$ molecule transport, since in each cycle $2\left(\mathrm{H}_{2} \mathrm{O}\right)$ is produced, and an effective mechanism for removal of the water product would be to move two waters into the water pool region above the DNC in each cycle. Water exit pathways from the water pool above the DNC, in the region of the shifted water molecules, to the $\mathrm{p}$ side of the membrane have been identified by molecular dynamics simulations. ${ }^{57}$ Comparing the $\left(\mathrm{M} 1+2 \mathrm{H}_{2} \mathrm{O}\right)$ state with the $\mathrm{M} 2$ state, one can imagine that the water dimer shifted up only replaces the $\left(2 \mathrm{H}_{2} \mathrm{O}\right)$ already present in ( $\left.\mathrm{M1}+2 \mathrm{H}_{2} \mathrm{O}\right)$, which then is transferred to the bulk water pool above, and produces a net transit of $2\left(\mathrm{H}_{2} \mathrm{O}\right)$. We have done a rough calculation of the extra free energy cost for moving $2 \mathrm{H}_{2} \mathrm{O}$ from $\left(\mathrm{M1}+2 \mathrm{H}_{2} \mathrm{O}\right)$ into bulk water and find that it is small.

\subsection{The resting State $\mathrm{O}$ versus the cycling State $\mathrm{O}_{\mathrm{H}}{ }^{60}$}

As depicted in Fig. 6, the active cycling State $\mathbf{O}_{\mathbf{H}}$ can decay to the relaxed lower lying State $\mathbf{O}$ in a few milliseconds (in solution studies with RR) when the next one electron transfer $\left(1 \mathrm{e}^{-}\right)$to the DNC is delayed (or absent entirely). In the associated Resonance Raman spectra, the State $\mathbf{O}_{\mathbf{H}}$ signal (whose observation is enhanced by comparing the normal ${ }^{16} \mathrm{O}$ signal with the isotopic substitution ${ }^{18} \mathrm{O}$ signal starting from reactant $\mathrm{O}_{2}$ binding to State $\mathbf{R}$, following through the reaction cycle) is lost on formation of State $\mathbf{O}$. The resting State $\mathbf{O}$ is expected to be the same as that found in the resting "as isolated" system as formed in oxidizing conditions. By comparison, State $\mathbf{O}_{\mathbf{H}}$ is a metastable catalytically active state. The different characters of State $\mathbf{O}_{\mathbf{H}}$ versus State $\mathbf{O}$ were initially observed in kinetics studies using a combination of optical difference spectroscopy and electrometry with laser photoactivation over the cycle to follow the $1 \mathrm{e}^{-}$redox transitions $\mathbf{O}_{\mathbf{H}}+1 \mathrm{e}^{-} \rightarrow \mathbf{E}_{\mathbf{H}}$ compared to 
$\mathrm{O}+1 \mathrm{e}^{-} \rightarrow \mathbf{E} .^{94,95}$ In the following redox step which regenerates State $\mathbf{R}$, one additional electron is added to the active site, and if needed, a proton may move into the active site vicinity to protonate an $\mathrm{OH}^{-}$. The kinetics seen for $\mathbf{O}_{\mathbf{H}} \rightarrow \mathbf{E}_{\mathbf{H}}$ is different from that observed for $\mathbf{O} \rightarrow \mathbf{E}$. The first gives more efficient electron transfer, with the electron terminating at $\mathrm{Cu}_{\mathrm{B}}$, and proton transfer is more effective as well for both $b a_{3}$ and $a a_{3}$ type enzymes. In $a a_{3}$ type enzymes, proton pumping occurs just after State $\mathbf{O}_{\mathbf{H}}$, but not after State $\mathbf{0} .^{96-98}$ Based on these differences in kinetics, some substantial structural differences are expected between $\mathbf{O}_{\mathbf{H}}$ and $\mathbf{O}$, but these specific differences are not evident.

There are various X-ray crystal structures of State $\mathbf{O}$ (as isolated oxidized species) early on and analyses of the solvent or oxygen species in the DNC based on the observed electron density between $\mathrm{Fe}_{\mathrm{a} 3}$ and $\mathrm{Cu}_{\mathrm{B}}$, originally interpreted as a $\mathrm{H}_{2} \mathrm{O}$ and an $\mathrm{OH}^{-}$ligand between the metals. These include structures of bacterial $a a_{3}$ type $\mathrm{CcO}$ 's from Rhodobacter sphaeroides (Rs) and Paracoccus denitrificans (Pd). ${ }^{27,28}$ Later, based on higher-resolution X-ray crystal structures using synchrotron radiation of oxidized CcO's from Pd (PDB code 3HB3, $2.25 \AA$ resolution), ${ }^{29}$ and from bovine heart mitochondria (PDB code 2ZXW, 1.95 Å resolution), ${ }^{30}$ two research groups identified an elongated electron density bridging $\mathrm{Fe}_{\mathrm{a} 3}$ and $\mathrm{Cu}_{\mathrm{B}}$ in the DNC, and proposed that this is a peroxide dianion $\left(\mathrm{O}_{2}{ }^{2-}\right)$. All of these systems were crystallized from a buffer solution. Following on earlier structures of $b a_{3} \mathrm{CcO}$ crystallized from cryogenically stabilized solvent, ${ }^{21}$ higher resolution $(1.8-1.9 \AA)$ synchrotron X-ray crystal structures (PDB entries 3S8G and $3 \mathrm{~S} 8 \mathrm{~F})^{14}$ of $b a_{3} \mathrm{CcO}$ from $T t$ were obtained in lipidic cubic phase (LCP), which is more membrane-like compared to buffered detergent solutions. These also showed a similar elongated electron density. The O1-O2 distances obtained by modeling the structure into the observed electron density maps range from $1.52 \AA$ at the shortest for $b a_{3} T t$ to a range of 1.6-1.9 $\AA$ for other structures in $a a_{3} \mathrm{CcO}$ enzymes.

A recent low-dose X-ray structure on oxidized resting state $\mathrm{CcO}$ from bovine heart mitochondria also showed an apparent peroxide type ligand in the $\mathrm{DNC}^{31}$ and a similar species was seen in an X-ray free-electron laser (XFEL) experiment $(1.9 \AA$ resolution). ${ }^{32}$ While the absorbed power in this XFEL experiment is very high, the diffraction data is collected over the period of the XFEL pulse, which is extremely short, typically between $10 \mathrm{fs}$ and $50 \mathrm{fs}$, well before the crystal explodes from the longer term radiation damage. The delivered radiation dose is much less than in synchrotron experiments, where the dose is delivered over a much longer time, and the diffraction pattern data is also collected over an extended period. There are ways of mitigating the radiation damage in synchrotron experiments, including using multiple crystals, or irradiating different locations on a crystal. In contrast to synchrotron X-ray diffraction experiments, which are strongly reducing at the metals, because of electron recombination preferentially at those sites, XFELs experiments are strongly oxidizing at the metal sites because after metal ionization, there is little time for the electrons to recombine over the pulse duration.
Despite the conclusions discussed above, there are good reasons to be doubtful about the proposed peroxide ligand between $\mathrm{Fe}_{\mathrm{a} 3}$ and $\mathrm{Cu}_{\mathrm{B}}$. In our view, this concern is particularly strong if the peroxide is proposed to be pre-existing prior to $\mathrm{X}$-ray irradiation. A pre-existing peroxide bonded to $\mathrm{Fe}$ and $\mathrm{Cu}$ does not fit well with the known chemistry of either $a a_{3}$ type or $b a_{3}$ type $\mathrm{CcO}$. When oxidized $\mathrm{CcO}$ is exposed to $\mathrm{HOOH}$ in $a a_{3}$ $\mathrm{CcO}$ proteins, it reaches the $\mathrm{DNC}$, and reacts with the $\mathrm{Fe}-\mathrm{Cu}$ center, generating the ferryl-oxo, $\mathrm{Cu}^{2+}$ tyrosine radical State $\mathbf{P}_{\mathbf{M}}$. By contrast, in $b a_{3}$ type $\mathrm{CcO}, \mathrm{HOOH}$ does not have access to the $\mathrm{Fe}-\mathrm{Cu}$ site at all. X-ray structures of the as isolated resting oxidized state (State $\mathbf{O}$ ) showing a non-reactive peroxide or hydroperoxide then are contrary to this reaction chemistry. The active site positioning of the peroxide or hydroperoxide is also surprising. In the lipidic cubic phase structure solved for $b a_{3} \mathrm{CcO}$, the apparent $\mathrm{Fe}-\mathrm{O} 1$ distance is about $2.4 \AA$ and the $\mathrm{Cu}-\mathrm{O} 2$ distance is about $2.25 \AA$, both fairly weak. Further, the apparent O-O distance in the LCP $b a_{3}$ is $1.5 \AA$ or more; in other structures from $a a_{3}$ type enzymes, the observed range is very long 1.6-1.9 ̊; these last distances are not consistent with any known peroxo or hydroperoxo type species, and yet these are much too short for hydrogen bonding between waters or $\mathrm{OH}^{-} \cdots \mathrm{H}_{2} \mathrm{O}$ bonds. In our earlier work on this problem, ${ }^{54}$ our group proposed that the peroxide or hydroperoxide (preferably the latter) could be formed by X-ray radiation induced radical reactions near the metals, and further stabilized by the cryogenic temperatures near that of liquid nitrogen. We learned later that X-ray absorption and ionization is enhanced for photon energies near and above the metal K-edge energy, and the X-ray irradiation photon energy typically used is above both the $\mathrm{Fe}$ and $\mathrm{Cu} \mathrm{K}$ edge ionization threshold. $\mathrm{Fe}$ and $\mathrm{Cu} \mathrm{K}$ edge ionization can lead to Auger ionization at the metals, and to various transferred Auger effects producing radicals in bonded or nearby atoms. These effects can be very fast, even on the 10-50 fs XFEL time scale, ${ }^{99}$ and may be observable, depending on the total radiation flux absorbed. However, the total X-ray radiation absorbed in the recent XFEL experiments is comparatively low, so that only about $10 \%$ or less of the $\mathrm{Fe}$ and $\mathrm{Cu}$ atoms will undergo core $\mathrm{M}(1 \mathrm{~s})$ ionization. While some effects due to X-ray irradiation in the XFEL experiments may be observable with careful attention to the time course, these effects are not likely to be the dominant effects in the observed diffraction pattern, since this pattern represents an average over many billions of $\mathrm{DNC} \mathrm{Fe-Cu}$ sites in the crystal. Instead, we have explored the possibility that a single water molecule is weakly bonded alternatively to $\mathrm{Fe}_{\mathrm{a} 3}{ }^{3+}$ and $\mathrm{Cu}_{\mathrm{B}}{ }^{2+}$ in the resting oxidized state. ${ }^{60}$ The apparent peroxide molecule is then predicted to be a consequence of a superposition of $\mathrm{H}_{2} \mathrm{O}$ positions between $\mathrm{Fe}$ and $\mathrm{Cu}$ from static and dynamic disorder. We have found that the potential energy surface between the $\mathrm{Fe}_{\mathrm{a}}$ and $\mathrm{Cu}_{\mathrm{B}}$ is very flat and the $\mathrm{H}_{2} \mathrm{O}$ to metal bonding is weak. This holds true whether or not this $\mathrm{H}_{2} \mathrm{O}$ is hydrogen bonded to another water molecule outside of the direct path between $\mathrm{Fe}$ and $\mathrm{Cu}$. Fig. 14 presents a superposition of our DFT calculated structures along this path with the observed electron density map derived from the published LCP high resolution (1.8 $\mathrm{\AA})$ synchrotron X-ray structure of $b a_{3} \mathrm{CcO} .^{14}$ 


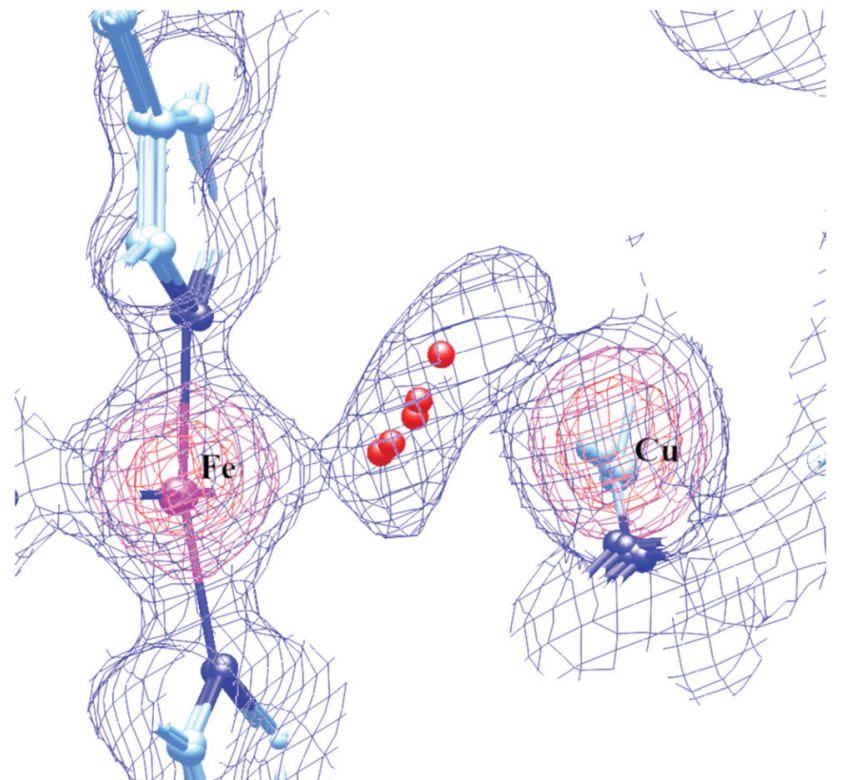

Fig. 14 The overlap of the electron density map that was reconstructed from the oxidized $\mathrm{Tt} b \mathrm{a}_{3} \mathrm{X}$-ray crystal structure $358 \mathrm{G}^{14}$ data file with our calculated resting $\mathbf{O}$ state DNC structures, in which a water molecule resides in different locations between the $\mathrm{Fe}_{a 3}{ }^{3+}$ and $\mathrm{Cu}_{\mathrm{B}}{ }^{2+}$ sites with very similar energies. Reprinted from Fig. 7 of ref. 60, https://pubs.acs.org/doi/ 10.1021/acs.inorgchem.0c00724, copyright (C) 2020 American Chemical Society (further permissions for reusing this figure should be directed to the ACS).

Our conclusion here is that the State $\mathbf{O}_{\mathbf{H}} \rightarrow$ State $\mathbf{O}$ transition is probably a slow protonation of the bridging $\mathrm{OH}^{-}$in State $\mathbf{O}_{\mathbf{H}}$, resulting in a water $\left(\mathrm{H}_{2} \mathrm{O}\right)$ weakly coordinated alternatively to $\mathrm{Fe}_{\mathrm{a} 3}$ or $\mathrm{Cu}_{\mathrm{B}}$. This apparently disrupts the electron transfer path to $\mathrm{Cu}_{\mathrm{B}}$.

\subsection{Features of state $\mathrm{O}$ and state $\mathrm{R}$ synchrotron $\mathrm{X}$-ray structures in $\mathrm{Tt} \mathrm{ba}_{3} \mathrm{CcO}$}

Very recently, our group, in collaboration with a group at SSRL completed new high resolution synchrotron X-ray structures of State $\mathbf{O}$ and State $\mathbf{R}$ in $b a_{3} \mathrm{CcO}$ from $T t$. This work is undergoing final analysis now. We do want to emphasize some features that we have observed in common with earlier structures of $b a_{3}$ and found also in $a a_{3}$ structures. Confirming previous lower resolution work, ${ }^{22}$ we find that Fe sites both in heme $b$ and heme $a_{3}$ are rapidly X-ray reduced from the original $\mathrm{Fe}^{3+}$ to $\mathrm{Fe}^{2+}$ based on microspectrophotometer absorption spectra, and these are the heme Fe states in the final X-ray structure. The State $\mathbf{O}$ structure is then referred to as State $\mathbf{O}_{(\mathbf{P R})}$, since it is at least partially reduced in the dinuclear complex region. The optical absorption observed at heme $a_{3}$ is consistent with having a 6-coordinate $\mathrm{Fe}^{2+}$, and we expect that this reflects $\mathrm{Fe}^{2+}-\mathrm{H}_{2} \mathrm{O}$ binding. The $\mathrm{Cu}_{\mathrm{B}}$ site does not have an observable optical spectroscopic signal at present, and so we cannot determine its redox state in this X-ray structure. After chemical reduction of the crystal at room temperature over an extended time, and freezing in liquid nitrogen, the fully reduced State $\mathbf{R}$ ((also called $\mathbf{R}_{(\mathbf{C R})}$ to indicate Chemical Reduction)) exhibits different optical spectra at $\mathrm{Fe}_{\mathrm{a} 3}$, consistent with a 5-coordinate $\mathrm{Fe}^{2+}$, and the solved X-ray structure shows no waters directly between $\mathrm{Fe}_{\mathrm{a} 3}$ and $\mathrm{Cu}_{\mathrm{B}}$, again consistent with the structure determined at lower resolution. This structure of State $\mathbf{R}$ has features in common with the chemically reduced forms of bovine mitochondrial $a a_{3}$ and of Rhodobacter sphaeroides $a a_{3} \mathrm{C} c \mathrm{O} .^{100,101}$

A new water (W1) is observed in State $\mathbf{R}$ within close hydrogen bonding distance to Tyr237 compared to State $\mathbf{O}_{(\mathbf{P R})}$. W1 is located about $4 \AA$ from $\mathrm{Cu}_{\mathrm{B}}$ and $\mathrm{Fe}_{\mathrm{a} 3}$, and similarly about $4.3 \AA$ from the oxygen position in the next states of the reaction cycle. It is also about $4 \AA$ from the Thr302(O) which is H-bonded to His282, a $\mathrm{Cu}_{\mathrm{B}}$ ligand. This hydrogen bond positioning indicates two possible input pathways for protons binding to oxygen species or hydroxyl groups in the DNC reaction chamber area between $\mathrm{Fe}_{\mathrm{a} 3}$ and $\mathrm{Cu}_{\mathrm{B}}$.

\subsection{The path from State $\mathbf{R} \rightarrow$ State $\mathbf{A} \rightarrow$ Peroxo $\rightarrow$ Hydroperoxo}

From State $\mathbf{R}$, molecular $\mathrm{O}_{2}$ binding produces State $\mathbf{A}$. How then are the next States Peroxo and Hydroperoxo formed, and what is the proton pathway in? In recent work by Schaefer et al. ${ }^{102}$ and earlier work by Adam et al., ${ }^{82}$ this group proposed that after formation of the Peroxo state, a proton enters via an $\mathrm{H}$-bonded chain from the special tyrosine to a water essentially like W1 discussed above, and this pathway leads to proton transfer to the $\mathrm{O} 1$ bonded to $\mathrm{Fe}_{\mathrm{a} 3}{ }^{3+}$ and then shifting to $\mathrm{O} 2$ bonded to $\mathrm{Cu}_{\mathrm{B}}{ }^{2+}$ prior to $\mathrm{O}-\mathrm{O}$ cleavage with the latter proton transfer being rate limiting. Although this pathway looks reasonable, we would like to propose an alternative, which does not require a pre-existing Peroxo bridge state, and uses some distinctive features of $\mathrm{Cu}_{\mathrm{B}}{ }^{+}$coordination chemistry. The $\mathrm{Cu}^{+}$redox state often exhibits lability in ligand binding, and we propose, starting from the State A (Superoxide bound) that His283 (see Fig. 15) dissociates from $\mathrm{Cu}_{\mathrm{B}}{ }^{+}$and protonates to $\mathrm{His}^{+}$, taking this proton from His282 via a ring flip, leaving His $282^{-}$as an unstable anion; flipping back, there will be a proton transfer from Thr302, generating Thr302 ${ }^{-}$, whose proton is restored by H-bonded waters or amino acid sidechains, going back to Tyr237 at the end of the proton uptake K-pathway. The $\mathrm{His}_{283^{+}}$state, once formed may be further stabilized by a cation $-\pi$ interaction with the nearby Trp229 ring. Meanwhile, electron transfer from $\mathrm{Cu}_{\mathrm{B}}{ }^{+}$to the superoxide ligand bonded to $\mathrm{Fe}_{\mathrm{a} 3}{ }^{3+}$ will be quickly followed by proton transfer from His $283^{+}$, and then the $\mathrm{Cu}_{\mathrm{B}}{ }^{2+}$ bond to His283 will reform. This mechanism is fairly analogous to one that we found for the reaction center in CuZn superoxide dismutase, which also involves a $\mathrm{Cu}^{+}-$His protonation and bond breakage, and then subsequent $\mathrm{Cu}^{2+}$-His bond formation after proton loss. ${ }^{103-107}$

\subsection{Radical transfer and proton pumping in State $\mathbf{P}_{\mathbf{M}}$}

Based on EPR spectra for two different tyrosine radicals that they observed in State $\mathbf{P}_{\mathbf{M}}$, Yu et al. ${ }^{108}$ proposed that a radical transfer mechanism in State $\mathbf{P}_{\mathbf{M}}$ could be essential to a proton pumping step in the transition $\mathbf{P}_{\mathbf{M}} \rightarrow \mathbf{P}_{\mathbf{R}}$. A similar mechanism could be operating in $b a_{3} \mathrm{CcO}$ from Tt. (See Fig. 15) In $T t b a_{3}$, 


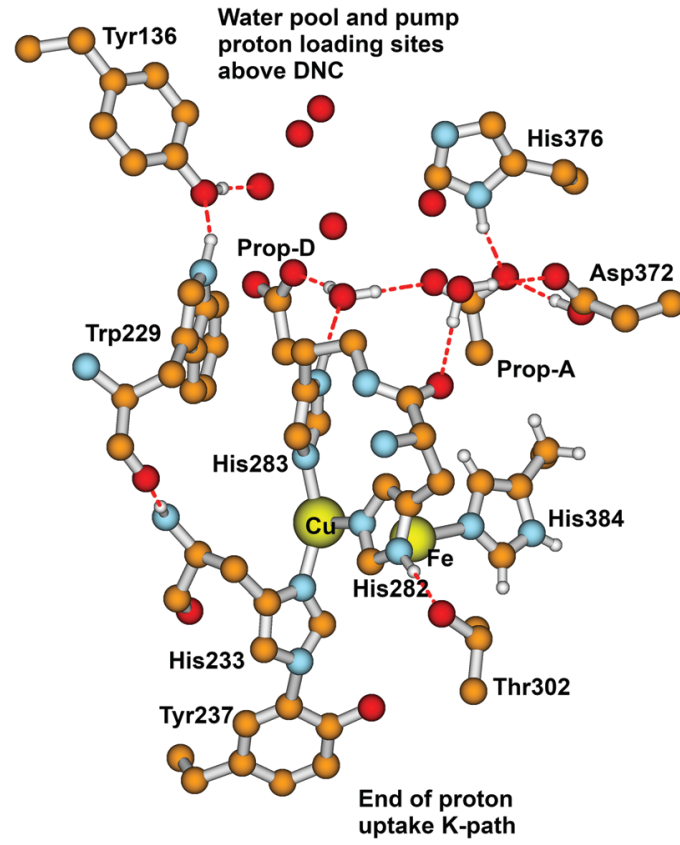

Fig. 15 Major residues and water molecules in the DNC of the Tt ba $\mathrm{X}$-ray crystal structure $3 \mathrm{~S} 8 \mathrm{G} .{ }^{14}$ For clarity, only prop-A and prop-D of the heme ring are presented here, the whole heme ring is not shown.

the relevant tyrosines are Tyr237 and Tyr136, the latter lying in the upper water pool with closely associated polar or charged amino acids capable of proton transfer. The tryptophan (Trp229) lies along a covalently bonded path from Tyr237 and His233 and further on, while the His233 main chain amide is also hydrogen bonded to the Trp229 carbonyl. One electron transfer from Trp229 to the Tyr237 radical will produce a Trp229 ${ }^{\circ}$ cation radical and a Tyr237 ${ }^{-}$anion. There is again an electronic stabilization of His283-Trp229, but now His is the $\pi$ system and $\operatorname{Trp}$ is the cation. The Trp $229^{\bullet+}$ radical will exert a strong electrostatic interaction with the Tyr136, causing the loss of its proton, becoming Tyr136 ${ }^{-}$, and the proton can then enter the upper pool of waters and polar amino acids. Whether or not there is a radical transfer between Tyr136 $6^{-}$and the Trp229 ${ }^{\bullet+}$ cation radical, there will later be an electron transfer from the heme $b \mathrm{Fe}^{2+}$.

To reset the system, there must be a proton resupplied from an effective proton pathway to Tyr136- . Here the pathways differ between $a a_{3}$ type, involving the $\mathrm{D}$ pathway (or perhaps the $\mathrm{H}$ pathway in mammalian mitochondria), while we have found a different proton pathway in $b a_{3}$ from $T t$ (see Fig. 15-17). The resupply pathway includes Asp372, Proprionate A (Prop A), His376 based on prior work. ${ }^{57}$ There are always at least two protons in this network, and sometimes three as we saw in the peroxide cleavage calculations $^{56}$ and our MD simulations. ${ }^{57}$ The proton pumping pathway from His376 to Tyr136 and out along water transport pathways is displayed in Yang et al., BBA, 2016 (see Fig. 16 and 17). ${ }^{57}$ Notably, the conformation of Tyr136 is sensitive to the protonation state of His376, either opening or blocking a water exit pathway, potentially acting as conformational gate against proton backflow. The proton exit path(s) are

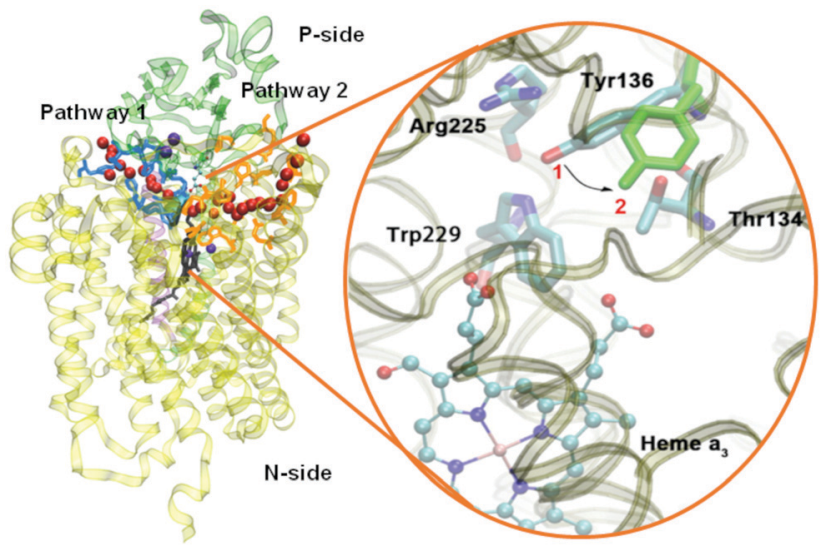

Fig. 16 Water exit pathways in $\mathrm{Tt} \mathrm{ba}_{3} \mathrm{CcO}$ identified from MD simulations. ${ }^{57}$ Tyr136 acts as a conformational gate.

probably similar in the water shift proton pumping mechanism, but these may differ in detail. We see that the description of the proton pumping process requires attention to the entire proton loading network (PLN) and associated pumping network, and not only a proton loading site (PLS).

\subsection{Limitations in current DFT calculations}

Our work and that from other groups have used a variety of standard DFT methods and exchange-correlation potentials. For our work, recent studies have used OLYP plus dispersion corrections, ${ }^{58-60}$ while in earlier papers, ${ }^{24,34}$ we tested PW91, B3LYP, B3LYP*, OPBE, OLYP for oxygen thermochemistry, and PW91 and B3LYP* for redox potentials for $\mathrm{Fe}^{3+, 2+}$ and $\mathrm{Cu}^{2+, 1+}$ of $\mathrm{Fe}_{\mathrm{a} 3}$ and $\mathrm{Cu}_{\mathrm{B}}$.

For the $\mathrm{O}_{2}$ thermochemistry, we evaluated the overall gas phase reaction

$$
\mathrm{O}_{2}+2 \mathrm{H}_{2} \rightarrow 2 \mathrm{H}_{2} \mathrm{O}
$$

This equation is the gas phase analogue of eqn (4). In our early work (see Table 3 of ref. 34), we found that there is a substantial deviation from experiment for the calculated $\Delta G$ for all these different DFT potentials, including OLYP in our 2014 paper. $^{24}$ Effectively the $\mathrm{O}_{2}$ binding is too strong so that the deviation in $\Delta G$ (Calc.-Exp.) ranges from 11.0 to $18.2 \mathrm{kcal} \mathrm{mol}^{-1}$, compared to the experimental $\Delta G$ of reaction equal to $-109.3 \mathrm{kcal} \mathrm{mol}^{-1}$. The potentials in order of increasing deviation are (PW91, B3LYP, B3LYP*, OPBE, OLYP). Meanwhile, breaking down the equation above into two steps, we have

$$
\begin{gathered}
\mathrm{O}_{2}+\mathrm{H}_{2} \rightarrow \mathrm{H}_{2} \mathrm{O}_{2} \\
\mathrm{H}_{2} \mathrm{O}_{2}+\mathrm{H}_{2} \rightarrow 2 \mathrm{H}_{2} \mathrm{O}
\end{gathered}
$$

We find that the OPBE error lies mainly in the $\pi$ bond breaking, and OLYP should be similar, while the corresponding errors for PW91, B3LYP, B3LYP* are mainly in the following $\sigma$ bond breaking. Clearly, these errors will affect the relative energies of different intermediates over the reaction cycle. In some steps, these errors are partly compensated by errors in the $\mathrm{Fe}_{\mathrm{a} 3}{ }^{3+, 2+}$ and $\mathrm{Cu}_{\mathrm{B}}{ }^{2+, 1+}$ redox potentials. In our 2014 paper, ${ }^{24}$ 

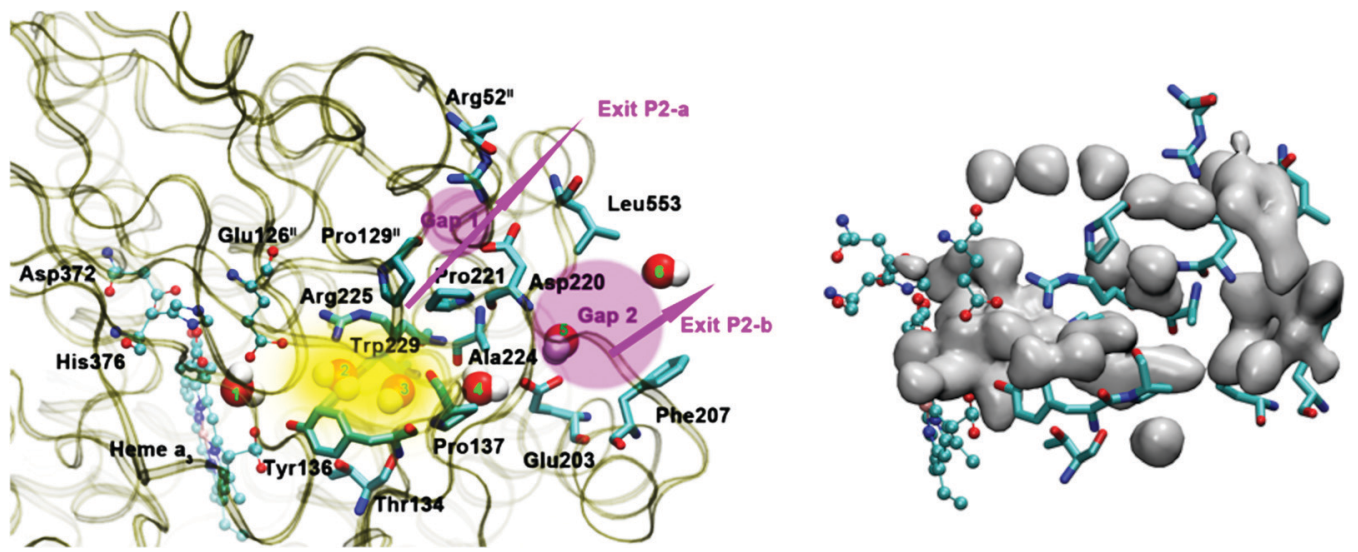

Fig. 17 Water exit pathway P2 obtained from MD simulations. ${ }^{57}$ Left: Detailed water pathway highlighting relevant residues. The pathway connects the water pool above the DNC to the outer side of the membrane via a water pocket (yellow) and two regions (pink, Gap1 and Gap2) that open towards the bulk solvent. Gap 1 is surrounded by residues Arg52", Pro129", Pro221, Asp220 and Leu553; Gap 2 is surrounded by residues Leu553, Asp220, Ala224, Glu203 and Phe207. Right: Water occupancy averaged over the entire trajectory (isosurface plot at 25\% occupancy), showing the path that connects the water pool to the protein exterior. Figure is taken with permission from Fig. 8 of ref. 57. https://doi.org/10.1016/j.bbabio.2016.06.005, copyright (C) 2016 Elsevier.

we made a rough estimate of the average redox potential error for $\mathrm{Fe}_{\mathrm{a} 3}$ and $\mathrm{Cu}_{\mathrm{B}}$ compared to what is known from experiment, finding the calculated redox potentials for $\mathrm{B}^{2} \mathrm{LYP}^{*}$ to be too negative by about $-0.3 \mathrm{~V}$, which is equivalent to a $\Delta G\left(1 \mathrm{e}^{-}\right.$ reduction) error of $+7 \mathrm{kcal} \mathrm{mol}^{-1}$. The errors in OPBE and OLYP for these redox steps are evidently of similar magnitude and direction. ${ }^{24}$ In forming State $\mathbf{A}$ from State $\mathbf{R}$ by binding $\mathrm{O}_{2}$, the error in oxidizing $\mathrm{Fe}_{\mathrm{a} 3}{ }^{2+}$ and reducing $\mathrm{O}_{2}$ to superoxide $\mathrm{O}_{2}{ }^{\bullet-}$ radical ion may partially cancel, but the reaction cycle has several states with large changes in electronic structure. For the corresponding reaction cycle for $a a_{3}$ type $\mathrm{CcO}$ using B3LYP* as the exchange-correlation potential, Blomberg ${ }^{109}$ has used a similar redox correction of $9 \mathrm{kcal} \mathrm{mol}^{-1}$ for $\mathrm{HS}$ heme- $\mathrm{Fe}^{3+, 2+}$ redox and other empirical corrections for $\mathrm{O}_{2}$ binding and other reaction steps. What is really needed are more accurate DFT potentials for use on the entire family of heme-copper oxidases and even more broadly throughout metallobiochemistry.

\section{Concluding remarks}

In this work, we have followed the catalytic reaction cycle of the dinuclear complex in $\mathrm{CcO}$ with particular focus on the $b a_{3}$ enzyme in Thermus thermophilus. Comparisons of proposed reaction pathways, including DFT calculated geometries, redox and protonation states, energies, and spectroscopic properties can be closely related to experimental X-ray structural and spectroscopic observations, clarifying the physical properties of various intermediates. Calculations of specific vibrational modes over the catalytic cycle in comparison with resonance Raman spectra have proven particularly valuable. ${ }^{59}$ We have developed some insights on proton transfers both into the reaction center $\mathrm{Fe}_{\mathrm{a} 3}-\mathrm{Cu}_{\mathrm{B}}$ active site and into the potential pathways for proton pumping. In $b a_{3} \mathrm{CcO}$, protons are delivered from the K pathway to the special Tyr237, and potentially on to Thr302, as we have proposed. ${ }^{24,34}$ At that point, the proton may move through an outer pathway to Asp372 and then to His376 or farther. Alternatively, it may reprotonate His282 which earlier transferred a proton to His283 in some states, in preparation for protonating intermediates within the reaction chamber. We have presented this proposal in some detail for the State A $\rightarrow$ Hydroperoxo transition, where the $\mathrm{Cu}_{\mathrm{B}}$ starts in the $\mathrm{Cu}^{+}$ cuprous state, emphasizing the lability of $\mathrm{Cu}^{+}$-histidine bonding. ${ }^{55}$ While this is perhaps the clearest and most likely example of a labile $\mathrm{Cu}_{\mathrm{B}}$ coordination, there are a number of other states of the catalytic cycle that are formally $\mathrm{Cu}^{2+}-\mathrm{Tyr}^{-}$.

When we look at these states with spin density population analysis, we see that all of these states have significant spin density on both $\mathrm{Cu}_{\mathrm{B}}$ and Tyr237. ${ }^{59,60}$ This spin distribution is indicative of a quantum admixed state involving a resonance between $\mathrm{Cu}^{2+}-\mathrm{Tyr}^{-}$(anion) and $\mathrm{Cu}^{+}-\mathrm{Tyr}^{\bullet}$ (radical). If the lower electronic ground state is mainly $\mathrm{Cu}^{2+}-\mathrm{Tyr}^{-}$(anion), then the activated intermediate state is mainly $\mathrm{Cu}^{+}-\mathrm{Tyr}^{\bullet}$ (radical), and the main question becomes how high in energy this latter state lies for specific intermediates and transitions in the reaction pathway, and to what extent each promotes proton transfer into the reaction chamber. There remains a great deal more work to be done involving reaction energetics, pathways and dynamics in $b a_{3} \mathrm{CcO}$ and the connections and contrasts with pathways in $a a_{3}$ from mitochondria and aerobic bacteria.

\section{Conflicts of interest}

There are no conflicts to declare.

\section{Acknowledgements}

This work is dedicated to the memory of Jim Fee and Dave Stout who made major contributions to the fields of metallobiochemistry and X-ray crystallography. They are and will be missed. Early on, LN appreciates the contribution of Dave Case 
to our first paper with J. A. Fee. We benefited also from discussions and emails with Per Siegbahn and Laura HunsickerWang, and later from extensive emails with Abhishek Dey and Marten Wikstrom. Most recently, we had very helpful email exchanges with Ken Karlin and Dennis Rousseau. For an extended period, we have had advice and collaboration on synchrotron X-ray structures with a group at Stanford Synchrotron Radiation Lightsource, in particular Tzanko Doukov and Aina Cohen. We also acknowledge discussions with Ross Walker, Åge Skjevik, Attila Fekete and Vinicius Cruzeiro. We thank the NIH for financial support (R01 GM100934) to L. N. and A. W. G., and thank The Scripps Research Institute for computational resources. This work also used the Extreme Science and Engineering Discovery Environment (XSEDE), which is supported by the National Science Foundation (grant number ACI-1053575, resources at the San Diego Supercomputer Center through award TG-CHE130010 to AWG).

\section{References}

1 O. M. H. Richter and B. Ludwig, Rev. Physiol., Biochem. Pharmacol., 2003, 147, 47-74.

2 V. M. Luna, Y. Chen, J. A. Fee and C. D. Stout, Biochemistry, 2008, 47, 4657-4665.

3 S. Iwata, C. Ostermeier, B. Ludwig and H. Michel, Nature, 1995, 376, 660-669.

4 T. Tsukihara, H. Aoyama, E. Yamashita, T. Tomizaki, H. Yamaguchi, K. Shinzawa-Itoh, R. Nakashima, R. Yaono and S. Yoshikawa, Science, 1996, 272, 1136-1144.

5 M. Svensson-Ek, J. Abramson, G. Larsson, S. Tornroth, P. Brzezinski and S. Iwata, J. Mol. Biol., 2002, 321, 329-339.

6 J. M. Zee and D. M. Glerum, Biochem. Cell Biol., 2006, 84, 859-869.

7 G. T. Babcock and M. Wikström, Nature, 1992, 356, 301-309.

8 S. Ferguson-Miller and G. T. Babcock, Chem. Rev., 1996, 96, 2889-2907.

9 B. G. Malmström, J. Biol. Inorg. Chem., 1998, 3, 339-343.

10 D. G. Nicholls and S. J. Ferguson, Bioenergetics 3, Academic Press, San Diego, CA, 2002.

11 J. Prebble, Trends Biochem. Sci., 2002, 27, 209-212.

12 M. K. F. Wikström, Nature, 1977, 266, 271-273.

13 T. A. Rouault and W. H. Tong, Trends Genet., 2008, 24, 398-407.

14 T. Tiefenbrunn, W. Liu, Y. Chen, V. Katritch, C. D. Stout, J. A. Fee and V. Cherezov, PLoS One, 2011, 6, e22348.

15 F. Francia, B. Khalfaoui-Hassani, P. Lanciano, F. Musiani, L. Noodleman, G. Venturoli and F. Daldal, Biochim. Biophys. Acta, Bioenerg., 2019, 1860, 167-179.

16 G. M. Ullmann, L. Noodleman and D. A. Case, J. Biol. Inorg. Chem., 2002, 7, 632-639.

17 M. E. Konkle, S. K. Muellner, A. L. Schwander, M. M. Dicus, R. Pokhrel, R. D. Britt, A. B. Taylor and L. M. HunsickerWang, Biochemistry, 2009, 48, 9848-9857.

18 L. I. Krishtalik, Biochim. Biophys. Acta, 2003, 1604, 13-21.
19 Y. B. Zu, M. M. J. Couture, D. R. J. Kolling, A. R. Crofts, L. D. Eltis, J. A. Fee and J. Hirst, Biochemistry, 2003, 42, 12400-12408.

20 T. Soulimane, G. Buse, G. P. Bourenkov, H. D. Bartunik, R. Huber and M. E. Than, EMBO J., 2000, 19, 1766-1776.

21 L. M. Hunsicker-Wang, R. L. Pacoma, Y. Chen, J. A. Fee and C. D. Stout, Acta Crystallogr., Sect. D: Biol. Crystallogr., 2005, 61, 340-343.

22 B. Liu, Y. Chen, T. Doukov, S. M. Soltis, C. D. Stout and J. A. Fee, Biochemistry, 2009, 48, 820-826.

23 R. Andersson, C. Safari, R. Dods, E. Nango, R. Tanaka, A. Yamashita, T. Nakane, K. Tono, Y. Joti, P. Bath, E. Dunevall, R. Bosman, O. Nureki, S. Iwata, R. Neutze and G. Branden, Sci. Rep., 2017, 7, 4518.

24 L. Noodleman, W.-G. Han Du, J. A. Fee, A. W. Götz and R. C. Walker, Inorg. Chem., 2014, 53, 6458-6472.

25 S. A. Siletsky, I. Belevich, A. Jasaitis, A. A. Konstantinov, M. Wikström, T. Soulimane and M. I. Verkhovsky, Biochim. Biophys. Acta, 2007, 1767, 1383-1392.

26 V. Rauhamäki and M. Wikström, Biochim. Biophys. Acta, 2014, 1837, 999-1003.

27 C. Ostermeier, A. Harrenga, U. Ermler and H. Michel, Proc. Natl. Acad. Sci. U. S. A., 1997, 94, 10547-10553.

28 L. Qin, C. Hiser, A. Mulichak, R. M. Garavito and S. Ferguson-Miller, Proc. Natl. Acad. Sci. U. S. A., 2006, 103, 16117-16122.

29 J. Koepke, E. Olkhova, H. Angerer, H. Muller, G. H. Peng and H. Michel, Biochim. Biophys. Acta, 2009, 1787, 635-645.

30 H. Aoyama, K. Muramoto, K. Shinzawa-Itoh, K. Hirata, E. Yamashita, T. Tsukihara, T. Ogura and S. Yoshikawa, Proc. Natl. Acad. Sci. U. S. A., 2009, 106, 2165-2169.

31 G. Ueno, A. Shimada, E. Yamashita, K. Hasegawa, T. Kumasaka, K. Shinzawa-Itoh, S. Yoshikawa, T. Tsukihara and M. Yamamoto, J. Synchrotron Radiat., 2019, 26, 912-921.

32 K. Hirata, K. Shinzawa-Itoh, N. Yano, S. Takemura, K. Kato, M. Hatanaka, K. Muramoto, T. Kawahara, T. Tsukihara, E. Yamashita, K. Tono, G. Ueno, T. Hikima, H. Murakami, Y. Inubushi, M. Yabashi, T. Ishikawa, M. Yamamoto, T. Ogura, H. Sugimoto, J. R. Shen, S. Yoshikawa and H. Ago, Nat. Methods, 2014, 11, 734-U174.

33 H. Y. Chang, J. Hemp, Y. Chen, J. A. Fee and R. B. Gennis, Proc. Natl. Acad. Sci. U. S. A., 2009, 106, 16169-16173.

34 J. A. Fee, D. A. Case and L. Noodleman, J. Am. Chem. Soc., 2008, 130, 15002-15021.

35 I. Szundi, C. Funatogawa, J. A. Fee, T. Soulimane and O. Einarsdottir, Proc. Natl. Acad. Sci. U. S. A., 2010, 107, 21010-21015.

36 T. Egawa, Y. Chen, J. A. Fee, S. R. Yeh and D. L. Rousseau, Biochim. Biophys. Acta, 2012, 1817, 666-671.

37 S. Yoshikawa and A. Shimada, Chem. Rev., 2015, 115, 1936-1989.

38 M. Wikström, K. Krab and V. Sharma, Chem. Rev., 2018, 118, 2469-2490.

39 I. Ishigami, M. Hikita, T. Egawa, S. R. Yeh and D. L. Rousseau, Biochim. Biophys. Acta, Bioenerg., 2015, 1847, 98-108. 
40 S. Han, Y. C. Ching and D. L. Rousseau, Proc. Natl. Acad. Sci. U. S. A., 1990, 87, 2491-2495.

41 S. H. Han, Y. C. Ching and D. L. Rousseau, Biochemistry, 1990, 29, 1380-1384.

42 T. Ogura, S. Takahashi, K. Shinzawa-Itoh, S. Yoshikawa and T. Kitagawa, J. Am. Chem. Soc., 1990, 112, 5630-5631.

43 T. Ogura, S. Takahashi, S. Hirota, K. Shinzawa-Itoh, S. Yoshikawa, E. H. Appelman and T. Kitagawa, J. Am. Chem. Soc., 1993, 115, 8527-8536.

44 C. Varotsis, W. H. Woodruff and G. T. Babcock, J. Am. Chem. Soc., 1989, 111, 6439-6440.

45 D. A. Proshlyakov, T. Ogura, K. Shinzawa-Itoh, S. Yoshikawa, E. H. Appelman and T. Kitagawa, J. Biol. Chem., 1994, 269, 29385-29388.

46 D. A. Proshlyakov, M. A. Pressler and G. T. Babcock, Proc. Natl. Acad. Sci. U. S. A., 1998, 95, 8020-8025.

47 T. Ogura and T. Kitagawa, Biochim. Biophys. Acta, 2004, 1655, 290-297.

48 E. Pinakoulaki, V. Daskalakis, T. Ohta, O. M. H. Richter, K. Budiman, T. Kitagawa, B. Ludwig and C. Varotsis, J. Biol. Chem., 2013, 288, 20261-20266.

49 S. W. Han, Y. C. Ching and D. L. Rousseau, Nature, 1990, 348, 89-90.

50 S. Han, S. Takahashi and D. L. Rousseau, J. Biol. Chem., 2000, 275, 1910-1919.

51 T. Kitagawa, J. Inorg. Biochem., 2000, 82, 9-18.

52 C. Varotsis and G. T. Babcock, Biochemistry, 1990, 29, 7357-7362.

53 C. J. T. de Grotthuss, Ann. Chim., 1806, 58, 54-73.

54 W.-G. Han Du and L. Noodleman, Inorg. Chem., 2013, 52, 14072-14088.

55 W.-G. Han Du and L. Noodleman, Inorg. Chem., 2015, 54, 7272-7290.

56 W.-G. Han Du, A. W. Götz, L. H. Yang, R. C. Walker and L. Noodleman, Phys. Chem. Chem. Phys., 2016, 18, 21162-21171.

57 L. H. Yang, A. A. Skjevik, W.-G. Han Du, L. Noodleman, R. C. Walker and A. W. Götz, Biochim. Biophys. Acta, Bioenerg., 2016, 1857, 1594-1606.

58 W.-G. Han Du, A. W. Götz and L. Noodleman, Inorg. Chem., 2018, 57, 1048-1059.

59 W.-G. Han Du, A. W. Götz and L. Noodleman, Inorg. Chem., 2019, 58, 13933-13944.

60 W.-G. Han Du, D. McRee, A. W. Götz and L. Noodleman, Inorg. Chem., 2020, 59, 8906-8915.

61 E. J. Baerends, T. Ziegler, A. J. Atkins, J. Autschbach, O. Baseggio, D. Bashford, A. Bérces, F. M. Bickelhaupt, C. Bo, P. M. Boerrigter, L. Cavallo, C. Daul, D. P. Chong, D. V. Chulhai, L. Deng, R. M. Dickson, J. M. Dieterich, D. E. Ellis, M. van Faassen, L. Fan, T. H. Fischer, A. Förster, C. Fonseca Guerra, M. Franchini, A. Ghysels, A. Giammona, S. J. A. van Gisbergen, A. Goez, A. W. Götz, J. A. Groeneveld, O. V. Gritsenko, M. Grüning, S. Gusarov, F. E. Harris, P. van den Hoek, Z. Hu, C. R. Jacob, H. Jacobsen, L. Jensen, L. Joubert, J. W. Kaminski, G. van Kessel, C. König, F. Kootstra, A. Kovalenko, M. V. Krykunov, E. van Lenthe, D. A. McCormack, A. Michalak, M. Mitoraj, S. M. Morton,
J. Neugebauer, V. P. Nicu, L. Noodleman, V. P. Osinga, S. Patchkovskii, M. Pavanello, C. A. Peeples, P. H. T. Philipsen, D. Post, C. C. Pye, H. Ramanantoanina, P. Ramos, W. Ravenek, M. Reimann, J. I. Rodríguez, P. Ros, R. Rüger, P. R. T. Schipper, D. Schlüns, H. van Schoot, G. Schreckenbach, J. S. Seldenthuis, M. Seth, J. G. Snijders, M. Solà, M. Stener, M. Swart, D. Swerhone, V. Tognetti, G. te Velde, P. Vernooijs, L. Versluis, L. Visscher, O. Visser, F. Wang, T. A. Wesolowski, E. M. van Wezenbeek, G. Wiesenekker, S. K. Wolff, T. K. Woo and A. L. Yakovlev, $A D F$ 2017, SCM, Theoretical Chemistry, Vrije Universiteit, Amsterdam, The Netherlands, http://www.scm.com.

62 G. te Velde, F. M. Bickelhaupt, E. J. Baerends, C. F. Guerra, S. J. A. Van Gisbergen, J. G. Snijders and T. Ziegler, J. Comput. Chem., 2001, 22, 931-967.

63 C. F. Guerra, O. Visser, J. G. Snijders, G. te Velde and E. J. Baerends, in Methods and techniques for computational chemistry, ed. E. Clementi and C. Corongiu, STEF, Cagliari, 1995, pp. 303-395.

64 L. Noodleman, J. Chem. Phys., 1981, 74, 5737-5743.

65 L. Noodleman and D. A. Case, Adv. Inorg. Chem., 1992, 38, 423-470.

66 L. Noodleman, T. Lovell, W.-G. Han, T. Liu, R. A. Torres and F. Himo, in Comprehensive Coordination Chemistry II, From Biology to Nanotechnology, ed. A. B. Lever, Elsevier Ltd, 2003, vol. 2, pp. 491-510.

67 S. Grimme, S. Ehrlich and L. Goerigk, J. Comput. Chem., 2011, 32, 1456-1465.

68 A. Klamt and G. Schüürmann, J. Chem. Soc., Perkin Trans. 2, 1993, 799-805.

69 A. Klamt, J. Phys. Chem., 1995, 99, 2224-2235.

70 A. Klamt and V. Jonas, J. Chem. Phys., 1996, 105, 9972-9981.

71 C. C. Pye and T. Ziegler, Theory Chem. Acc., 1999, 101, 396-408.

72 T. Soda, Y. Kitagawa, T. Onishi, Y. Takano, Y. Shigeta, H. Nagao, Y. Yoshioka and K. Yamaguchi, Chem. Phys. Lett., 2000, 319, 223-230.

73 M. Radoń and K. Pierloot, J. Phys. Chem. A, 2008, 112, 11824-11832.

74 K. H. Hopmann, L. Noodleman and A. Ghosh, Chem. - Eur. J., 2010, 16, 10397-10408.

75 A. Ghysels, D. Van Neck, V. Van Speybroeck, T. Verstraelen and M. Waroquier, J. Chem. Phys., 2007, 126, 224102.

76 A. Ghysels, D. Van Neck and M. Waroquier, J. Chem. Phys., 2007, 127, 164108.

77 R. M. Badger, J. Chem. Phys., 1935, 3, 710-714.

78 I. Mayer, Chem. Phys. Lett., 1983, 97, 270-274.

79 J. P. Collman, J. I. Brauman, T. R. Halbert and K. S. Suslick, Proc. Natl. Acad. Sci. U. S. A., 1976, 73, 3333-3337.

80 J. P. Collman, K. E. Berg, C. J. Sunderland, A. Aukauloo, M. A. Vance and E. I. Solomon, Inorg. Chem., 2002, 41, 6583-6596.

81 J. P. Collman, C. J. Sunderland, K. E. Berg, M. A. Vance and E. I. Solomon, J. Am. Chem. Soc., 2003, 125, 6648-6649.

82 S. M. Adam, I. Garcia-Bosch, A. W. Schaefer, S. K. Sharma, M. A. Siegler, E. I. Solomon and K. D. Karlin, J. Am. Chem. Soc., 2017, 139, 472-481.

83 S. E. V. Phillips, J. Mol. Biol., 1980, 142, 531-554. 
84 S. E. V. Phillips and B. P. Schoenborn, Nature, 1981, 292, 81-82.

85 H. E. Van Wart and J. Zimmer, J. Biol. Chem., 1985, 260, 8372-8377.

86 S. Hirota, T. S. Li, G. N. Phillips, J. S. Olson, M. Mukai and T. Kitagawa, J. Am. Chem. Soc., 1996, 118, 7845-7846.

87 M. Tsubaki, K. Nagai and T. Kitagawa, Biochemistry, 1980, 19, 379-385.

88 K. Nakamoto, I. R. Paeng, T. Kuroi, T. Isobe and H. Oshio, J. Mol. Struct., 1988, 189, 293-300.

89 T. Watanabe, T. Ama and K. Nakamoto, J. Phys. Chem., 1984, 88, 440-445.

90 W. D. Wagner, I. R. Paeng and K. Nakamoto, J. Am. Chem. Soc., 1988, 110, 5565-5567.

91 Y. Mizutani, S. Hashimoto, Y. Tatsuno and T. Kitagawa, J. Am. Chem. Soc., 1990, 112, 6809-6814.

92 J. E. Morgan, M. I. Verkhovsky, G. Palmer and M. Wikström, Biochemistry, 2001, 40, 6882-6892.

93 A. L. Woelke, A. Wagner, G. Galstyan, T. Meyer and E. W. Knapp, Biophys. J., 2014, 107, 2177-2184.

94 S. A. Siletsky, I. Belevich, N. P. Belevich, T. Soulimane and M. Wikstrom, Biochim. Biophys. Acta, 2017, 1858, 915-926.

95 M. I. Verkhovsky, A. Jasaitis, M. L. Verkhovskaya, J. E. Morgan and M. Wikstrom, Nature, 1999, 400, 480-483.

96 D. Bloch, I. Belevich, A. Jasaitis, C. Ribacka, A. Puustinen, M. I. Verkhovsky and M. Wikström, Proc. Natl. Acad. Sci. U. S. A., 2004, 101, 529-533.

97 I. Belevich, D. A. Bloch, N. Belevich, M. Wikström and M. I. Verkhovsky, Proc. Natl. Acad. Sci. U. S. A., 2007, 104, 2685-2690.
98 S. A. Siletsky, I. Belevich, M. Wikström, T. Soulimane and M. I. Verkhovsky, Biochim. Biophys. Acta, Bioenerg., 2009, 1787, 201-205.

99 V. Stumpf, K. Gokhberg and L. S. Cederbaum, Nat. Chem., 2016, 8, 237-241.

100 I. Ishigami, A. Lewis-Ballester, A. Echelmeier, G. Brehm, N. A. Zatsepin, T. D. Grant, J. D. Coe, S. Lisova, G. Nelson, S. Zhang, Z. F. Dobson, S. Boutet, R. G. Sierra, A. Batyuk, P. Fromme, R. Fromme, J. C. H. Spence, A. Ros, S. R. Yeh and D. L. Rousseau, Proc. Natl. Acad. Sci. U. S. A., 2019, 116, 3572-3577.

101 L. Qin, J. Liu, D. A. Mills, D. A. Proshlyakov, C. Hiser and S. Ferguson-Miller, Biochemistry, 2009, 48, 5121-5130.

102 A. W. Schaefer, A. C. Roveda, Jr., A. Jose and E. I. Solomon, J. Am. Chem. Soc., 2019, 141, 10068-10081.

103 J. A. Tainer, E. D. Getzoff, J. S. Richardson and D. C. Richardson, Nature, 1983, 306, 284-287.

104 P. J. Hart, M. M. Balbirnie, N. L. Ogihara, A. M. Nersissian, M. S. Weiss, J. S. Valentine and D. Eisenberg, Biochemistry, 1999, 38, 2167-2178.

105 D. S. Shin, M. Didonato, D. P. Barondeau, G. L. Hura, C. Hitomi, J. A. Berglund, E. D. Getzoff, S. C. Cary and J. A. Tainer, J. Mol. Biol., 2009, 385, 1534-1555.

106 J. J. Perry, D. S. Shin, E. D. Getzoff and J. A. Tainer, Biochim. Biophys. Acta, 2010, 1804, 245-262.

107 R. Konecny, J. Li, C. L. Fisher, V. Dillet, D. Bashford and L. Noodleman, Inorg. Chem., 1999, 38, 940-950.

108 M. A. Yu, T. Egawa, K. Shinzawa-Itoh, S. Yoshikawa, V. Guallar, S. R. Yeh, D. L. Rousseau and G. J. Gerfen, J. Am. Chem. Soc., 2012, 134, 4753-4761.

109 M. R. A. Blomberg, Biochemistry, 2019, 58, 2028-2038. 